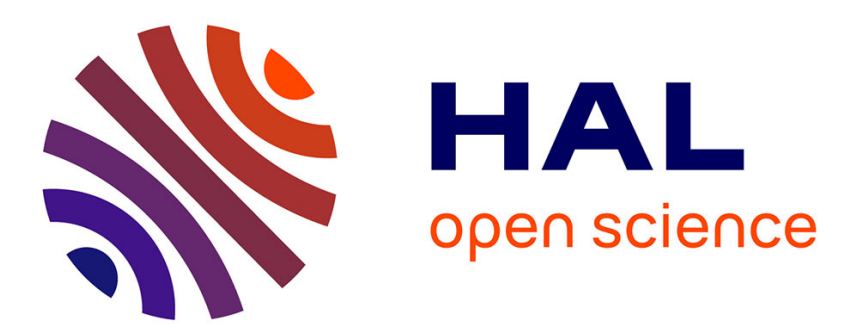

\title{
Tuning the Composition of FeCo Nanoparticle Heating Agents for Magnetically Induced Catalysis
}

Julien Marbaix, Nicolas Mille, Lise-Marie Lacroix, Juan Manuel Asensio, Pier-Francesco Fazzini, Katerina Soulantica, Julian Carrey, Bruno Chaudret

\section{- To cite this version:}

Julien Marbaix, Nicolas Mille, Lise-Marie Lacroix, Juan Manuel Asensio, Pier-Francesco Fazzini, et al.. Tuning the Composition of FeCo Nanoparticle Heating Agents for Magnetically Induced Catalysis. ACS Applied Nano Materials, In press, 10.1021/acsanm.0c00444 . hal-02536608

\section{HAL Id: hal-02536608 https://hal.science/hal-02536608}

Submitted on 8 Apr 2020

HAL is a multi-disciplinary open access archive for the deposit and dissemination of scientific research documents, whether they are published or not. The documents may come from teaching and research institutions in France or abroad, or from public or private research centers.
L'archive ouverte pluridisciplinaire HAL, est destinée au dépôt et à la diffusion de documents scientifiques de niveau recherche, publiés ou non, émanant des établissements d'enseignement et de recherche français ou étrangers, des laboratoires publics ou privés. 


\title{
Tuning the Composition of FeCo Nanoparticle Heating Agents for Magnetically Induced Catalysis
}

Julien Marbaix, Nicolas Mille, Lise-Marie Lacroix, Juan M. Asensio, Pier-Francesco Fazzini, Katerina Soulantica*, Julian Carrey*, Bruno Chaudret*

LPCNO, Université de Toulouse, CNRS, INSA, UPS, 135 avenue de Rangueil, 31077 Toulouse, France.

$\mathrm{FeCo}$, nanoparticle, magnetic heating, catalysis, $\mathrm{CO}_{2}$ hydrogenation, propane dehydrogenation

\begin{abstract}
Magnetic heating by nanoparticles has recently been successfully employed in heterogeneous catalysis. In such processes, the maximum temperature that can be reached depends on the Curie temperature $\left(T_{\mathrm{c}}\right)$ of the heating material. Here, in order to extend the range of accessible temperatures and consequently the range of possible reactions, to those requiring high temperatures, we developed and fully characterized a series of FeCo nanoparticles containing different concentrations of cobalt, in order to tune their magnetic properties and $T \mathrm{c}$. Their efficiency is compared to that of iron carbide nanoparticles, which display a lower $T \mathrm{c}$. Specific Absorption Rate (SAR) measurements as a function of temperature, performed using a homemade pyrometer-based setup, clearly show that, although the heating power of iron carbide
\end{abstract}


nanoparticles is higher at room temperature, it decreases more rapidly with temperature than that of iron cobalt nanoparticles, in agreement with their lower Tc. In a showcase, $\mathrm{Fe}_{0.5} \mathrm{Co}_{0.5}$ nanoparticles allow, in addition to $\mathrm{CO}_{2}$ hydrogenation, dry reforming of propane and methane, and dehydrogenation of propane, these reactions requiring temperatures of $350^{\circ} \mathrm{C}, 600^{\circ} \mathrm{C}$ and $700^{\circ} \mathrm{C}$ respectively. Furthermore, the use of $\mathrm{Fe}_{0.5} \mathrm{Co}_{0.5}$ nanoparticles is less energy demanding, as it allows carrying out $\mathrm{CO}_{2}$ hydrogenation at lower magnetic fields and at frequencies as low as $100 \mathrm{kHz}$. Dry reforming of methane and propane were carried out in the presence of a $\mathrm{Ni}$ nanoparticle-based catalyst whereas dehydrogenation of propane required as a catalyst PtSn nanoparticles synthesized through an organometallic route. $\mathrm{Fe}_{0.5} \mathrm{Co}_{0.5}$ nanoparticles can therefore be used as universal heating agents allowing performing reactions up to ca. $700^{\circ} \mathrm{C}$ upon association with the appropriate catalyst.

\section{INTRODUCTION}

Magnetic heating of nanoparticles (NPs) has been investigated for decades ${ }^{1-3}$, mostly for medical applications. More recently, it has been shown that magnetically induced heating could be exploited in catalysis, using iron oxide NPs in solution, ${ }^{4,5}$ or iron alloy NPs for gas-phase reactions. $^{6-12}$ It has been suggested that heating the catalytic system by magnetic induction confers a major advantage in terms of activation rate: magnetic NPs reach very rapidly, in the ms range, their steady state temperature and the system can be operational within a few minutes, versus hours for traditional heating. This rapid response should enable an efficient way of integrating this technology in hydrogen generation from renewable energies since it is compatible with their intermittent availability. ${ }^{13}$ An additional major advantage of this method is 
that since the heat is directly supplied to the system, and provided that losses are minimized, the reaction is assumed to be limited only by kinetics and not by heat transfer, as shown for the efficient steam reforming of methane ${ }^{8}$ or $\mathrm{CO}_{2}$ hydrogenation. ${ }^{7}$ This technology requires designing nanoscale magnetic heating agents (NHAs) adapted to the catalytic conditions of each system. In particular, it requires to precisely tune the NHAs composition in order to control their heating properties, the attainable temperature in the catalytic bed, and the magnetic field necessary for the onset of heating. The Curie temperature $\left(T_{\mathrm{C}}\right)$ of the NHAs is a major parameter to tune in order to reach the desired temperature of a given reaction, as discussed by Vinum et al. in the case of methane steam reforming. ${ }^{9}$ For this reason, and considering their promising magnetic properties for application in microelectronics, ${ }^{14}$ we decided to evaluate the performances of $\mathrm{Fe}_{1-\mathrm{x}} \mathrm{Co}_{\mathrm{x}}$ alloy NPs for magnetic heating and compare them with those of $\mathrm{FeC}$ NPs in catalytic reactions occurring at different temperatures, namely $\mathrm{CO}_{2}$ hydrogenation, propane dry reforming (PDR), methane dry reforming (MDR) and propane dehydrogenation (PDH). Pure Fe exhibits a $T_{\mathrm{C}}$ of $750^{\circ} \mathrm{C}$ while that of $\mathrm{Co}$ is $1150^{\circ} \mathrm{C}$. Even if cobalt has the highest $T_{\mathrm{C}}$ it is too "hard" to allow efficient activation by magnetic fields of low amplitude. ${ }^{15}$ Concerning FeCo alloys $\left(\mathrm{Fe}_{1-\mathrm{x}} \mathrm{Co}_{\mathrm{x}}\right)$, Pfeifer et al. showed that an increase of the cobalt content in the alloy composition leads to an increase of the $T_{\mathrm{C}}$ up to $1000^{\circ} \mathrm{C}$ for $\mathrm{Fe}_{0.65} \mathrm{Co}_{0.35}{ }^{16} \mathrm{FeCo}$ nanowires of micron length and 35 to a few hundreds of nm diameter have been shown to heat upon magnetic excitation ${ }^{17}$ and have been used for biological applications. ${ }^{18} \mathrm{Fe}_{1-\mathrm{x}} \mathrm{Co}_{\mathrm{x}}$ alloy NPs are therefore more appropriate for the activation of reactions that require high temperatures than the previously used by our group FeC-NPs, the $T_{\mathrm{C}}$ of which depends on the specific carbide phase and evaluated to be in the range of $400-450{ }^{\circ} \mathrm{C} .{ }^{19}$ The NP composition, besides controlling $T_{\mathrm{C}}$ and therefore the maximum steady state temperature of the system under magnetic activation, also 
modifies the anisotropy and saturation magnetization of the NP, two parameters which strongly influence their heating power. ${ }^{20}$ As a consequence, the alloy composition, which allows reaching the highest temperature cannot be easily predicted since heating properties are the result of a complex combination between the temperature dependence of magnetization and of anisotropy.

The nano-alloys can be synthetized by an organometallic approach, which allows controlling the composition of the nanoparticles. Here we show that, using as $\mathrm{NHAs} \mathrm{Fe}_{0.5} \mathrm{Co}_{0.5}$-NPs, we can achieve the performances previously reached by $\mathrm{FeC}$ NHAs in the nickel catalyzed Sabatier reaction, even upon lowering the magnetic field amplitude. Furthermore, when associated with Ni NPs based catalysts, these FeCo-NPs can activate both PDR and MDR. Last but not least, the $\mathrm{PDH}$ reaction, which requires an even higher temperature, can be activated in the presence of Snpoisoned Pt NPs as catalysts. These results therefore demonstrate the versatility of FeCo NHAs displaying high $T_{\mathrm{C}}$ and high SAR to carry out magnetically induced catalytic reactions in a wide range of temperatures.

\section{RESULTS AND DISCUSSION}

\section{Tuning of the heating temperature reached by magnetic hyperthermia.}

\subsection{Structural properties of the heating agents}

The synthesis of the iron-based nanoparticles used as NHAs involves the reduction by hydrogen of molecular precursors in the presence of stabilizing ligands. (see Scheme 1 and Methods). Briefly, for iron and iron carbide NPs, the synthesis was carried out following

previously reported methods. ${ }^{7,21-24}$ The FeCo NPs were prepared by adapting a method recently developed in our group. ${ }^{14}$ Briefly, monodisperse $\mathbf{F e}_{0.5} \mathbf{C o}_{0.5}$-NPs were obtained by reducing 
under $\mathrm{H}_{2}\left[\mathrm{Fe}\left\{\mathrm{N}\left(\mathrm{SiMe}_{3}\right)_{2}\right\}_{2}\right]_{2}$ and $\left[\mathrm{Co}\left\{\mathrm{N}\left(\mathrm{SiMe}_{3}\right)_{2}\right\}_{2}(\mathrm{thf})\right]$ in the presence of hexadecylammonium chloride (HDAHCl) and hexadecylamine (HDA).

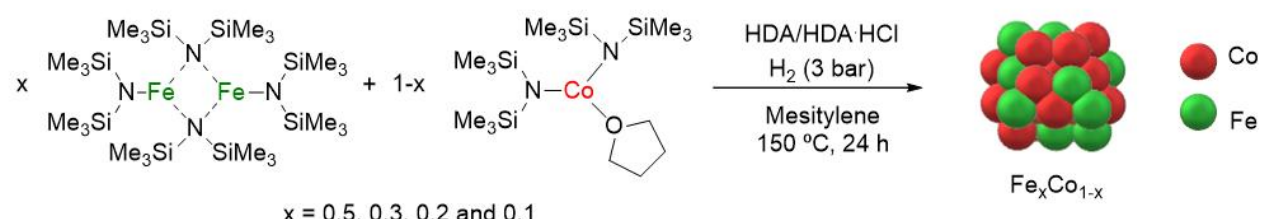

Scheme 1: Reaction outline for the synthesis of $\mathrm{Fe}_{\mathrm{y}} \mathrm{Co}_{\mathrm{x}}$ heating agents

Based on this synthesis and by adjusting the ratio of precursors, new $\mathrm{Fe}_{1-\mathrm{x}} \mathrm{Co}_{\mathrm{x}} \mathrm{NPs}, \mathrm{x}=0.1 / 0.2$ and 0.3: $\mathrm{Fe}_{0.9} \mathrm{Co}_{0.1}-\mathrm{NPs}, \mathrm{Fe}_{0.8} \mathrm{Co}_{0.2}-\mathrm{NPs}, \mathrm{Fe}_{0.7} \mathrm{Co}_{0.3}$-NPs of varied magnetic properties were prepared. Compared to the spherical $\mathbf{F e}_{0.5} \mathbf{C o}_{0.5}-\mathbf{N P s}$, the resulting $\mathrm{Fe}_{1-\mathrm{x}} \mathrm{Co}_{\mathrm{x}} \mathrm{NPs}(\mathrm{x}<0.5)$ are cubic in shape and grow up to $25 \mathrm{~nm}$ when the Co content is decreased, with an increased polydispersity (up to $\pm 5 \mathrm{~nm}$ ). The size increase upon decrease of the Co content can be explained by the different reduction kinetics of the two metals. Cobalt being easier to reduce, its amount determines the number of seeds formed in solution. The higher this number, the smaller the size of the final $\mathrm{Fe}_{1-\mathrm{x}} \mathrm{Co}_{\mathrm{x}} \mathrm{NPs}$ formed by subsequent reduction of iron on the Co seeds. The $\mathrm{Fe}(0)$ and FeC NPs size cannot be rationalized in the same context since they are prepared by a slightly different procedure that employs HDA/palmitic acid (PA) instead of HDA/ HDAHCl ligands. The stability of the species formed by changing the nature of the ligands influences the kinetics of the nucleation and growth. Transmission Electron Microscopy (TEM) images of the different NPs are shown on Figure 1. An overview of the composition and structural properties of the FeCo alloy NPs are given in Table 1 and more details can be found in Supporting Information (Table S1, Fig. S1 and Fig. S2). The size of the crystallites assessed by the Scherrer-calculation based on the X-Ray Diffractometry (XRD) are in good agreement with the size obtained by 
TEM, indicating a single crystalline structure of the $\mathrm{Fe}_{1-\mathrm{x}} \mathrm{Co}_{\mathrm{x}}$ NPs. Electron Energy Loss Spectroscopy (EELS) analysis shows a composition close to the targeted one with a Fe-Co core and in general an enrichment of the surface in Fe. The metal content of all powders is around 85\%. Microanalyses obtained by Inductively Coupled Plasma Mass Spectrometry (ICP-MS) agree with the EELS observations, both showing the progressive increase of Co concentration in the samples as the $\left[\mathrm{Co}\left\{\mathrm{N}\left(\mathrm{SiMe}_{3}\right)_{2}\right\}_{2}(\right.$ thf $\left.)\right]$ amount is increased in the initial solution.

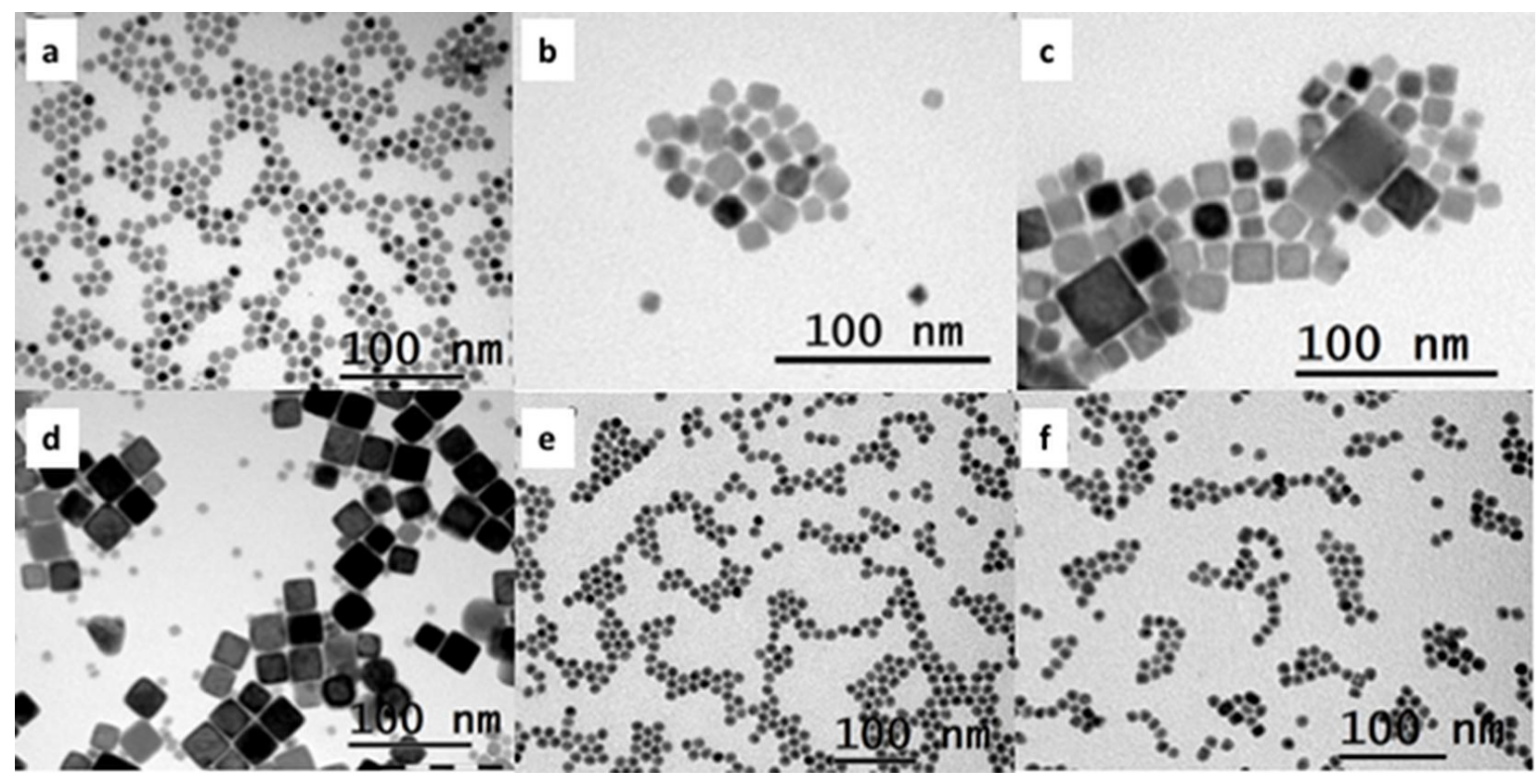

Figure 1. TEM micrographs of $\mathbf{F e}_{1-\mathrm{x}} \mathbf{C o}_{\mathbf{x}}-\mathbf{N P s}$ with $\mathrm{x}=$ (a) 0.5 ; (b) 0.3 ; (c) $0.2 ;$ (d) 0.1 ; (e) 0 and (f) FeC-NPs.

Table 1. Structural properties of the $\mathbf{F e}_{1-\mathrm{x}} \mathbf{C o}_{\mathbf{x}}-\mathbf{N P s}(\mathrm{x}=0.1 ; 0.2 ; 0.3 ; 0.5)$ used as HAs.

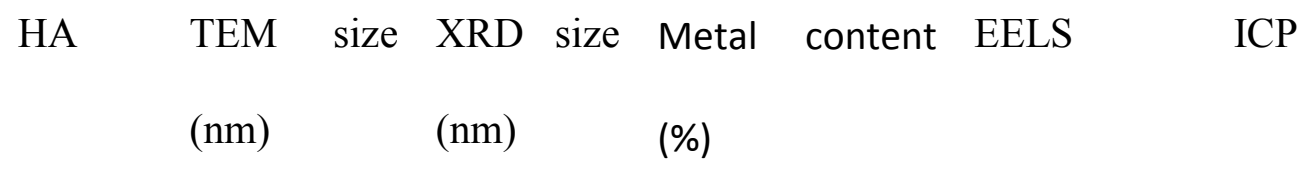




\begin{tabular}{lccccc}
\hline $\mathrm{Fe}_{0.5} \mathrm{C}$ & $10.2 \pm 0.7$ & 7.2 & 84.2 & $\mathrm{Fe}_{0.49} \mathrm{Co}_{0.51}$ & $\mathrm{Fe}_{0.49} \mathrm{Co}_{0.51}$ \\
$\mathrm{O}_{0.5}$ & & & & \\
$\mathrm{Fe}_{0.7} \mathrm{C}$ & $17 \pm 2.8$ & 12.2 & 83.1 & $\mathrm{Fe}_{0.77} \mathrm{Co}_{0.23}$ & $\mathrm{Fe}_{0.74} \mathrm{Co}_{0.26}$ \\
$\mathrm{O}_{0.3}$ & & & & \\
& & & & & \\
\hline $\mathrm{Fe}_{0.8} \mathrm{C}$ & $17.8 \pm 1.8$ & 16.9 & 90.7 & $\mathrm{Fe}_{0.86} \mathrm{Co}_{0.14}$ & $\mathrm{Fe}_{0.79} \mathrm{Co}_{0.21}$ \\
$\mathrm{o}_{0.2}$ & & & & & \\
\hline $\mathrm{Fe}_{0.9} \mathrm{C}$ & $22.9 \pm 2.5$ & 20.2 & 90.9 & & \\
$\mathrm{O}_{0.1}$ & & & & $\mathrm{Fe}_{0.92} \mathrm{Co}_{0.08}$ & $\mathrm{Fe}_{0.93} \mathrm{Co}_{0.07}$ \\
& & & & & \\
\end{tabular}

Mössbauer spectroscopy has been performed on the $\mathbf{F e}_{1-\mathbf{x}} \mathbf{C o}_{\mathbf{x}}-\mathbf{N P s}$ at $4 \mathrm{~K}$. FeC-NPs and $\mathbf{F e}_{\mathbf{0 . 5}} \mathbf{C o}_{0.5}$-NPs have been previously characterized, ${ }^{7,14,25}$ but the data concerning this composition are included in the present study for comparison purpose. The data fitting reveals different contributions related to a Co-concentration gradient, as the hyperfine field values vary from 33.8 $\mathrm{T}$ (Fe) up to $38 \mathrm{~T}$ (hyperfine fields reported for Fe-Co alloys). ${ }^{14,26,27} \mathrm{In}$ our case, the $34 \mathrm{~T}$ hyperfine field fraction varies from $53 \%$ in the case of $\mathrm{Fe}_{0.9} \mathrm{Co}_{0.1}$ down to $38 \%$ for $\mathrm{Fe}_{0.8} \mathrm{Co}_{0.2}$, $22.5 \%$ for $\mathrm{Fe}_{0.7} \mathrm{Co}_{0.3}$ and finally $22 \%$ for $\mathrm{Fe}_{0.5} \mathrm{Co}_{0.5}$ (See Figure 2). The fitting parameters can be found in Table S2. Thus, Mössbauer analyses of the $\mathrm{Fe}_{1-\mathrm{x}} \mathrm{Co}_{\mathrm{x}}$ alloys, in agreement with the structural analyses (EELS, ICP), clearly demonstrate a continuous alloying process and the progressive incorporation of Co into the Fe NPs upon increasing the cobalt fraction. 

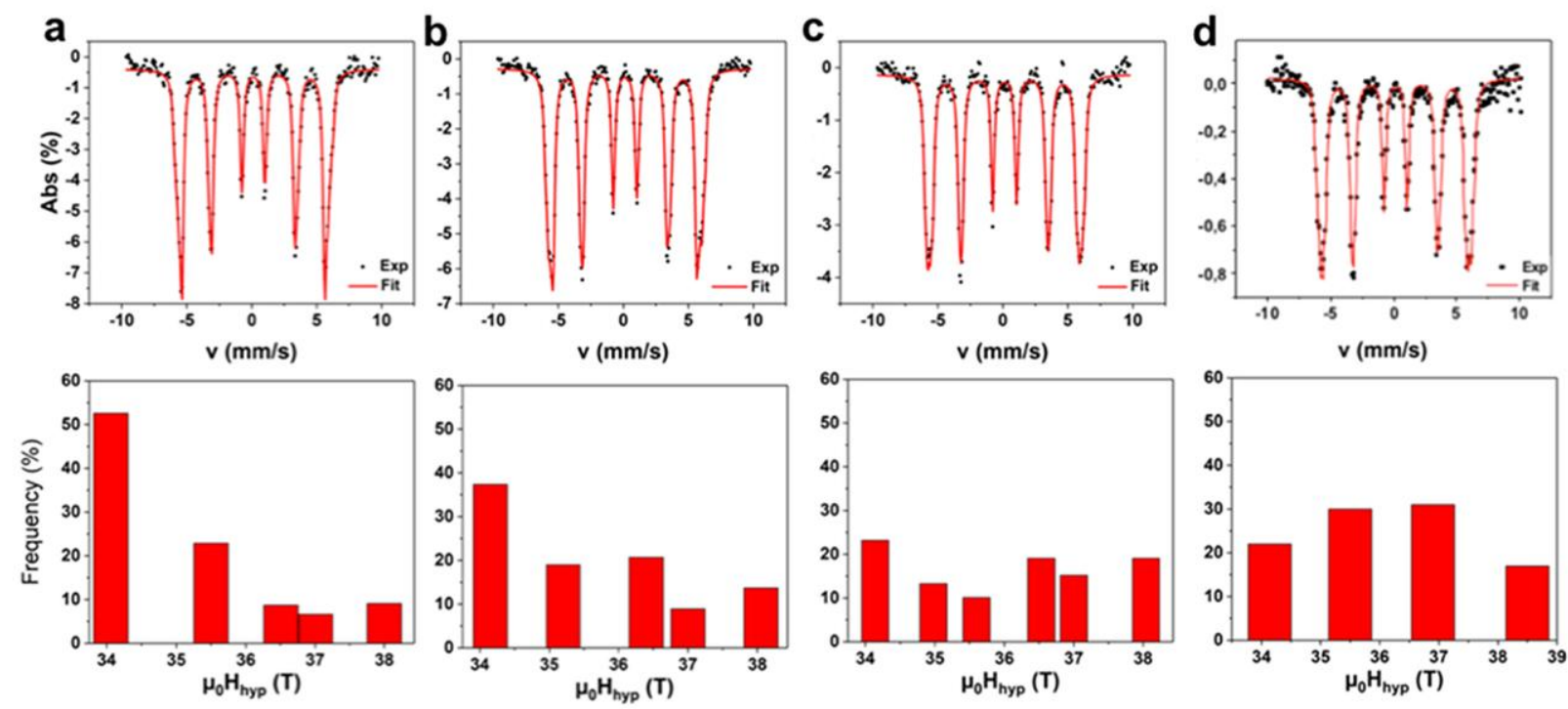

Figure 2. Mössbauer spectrometry performed at $5 \mathrm{~K}$ and fits of the spectrums with dedicated hyperfine field $\left(\mathrm{H}_{\mathrm{hyp}}\right)$ contribution of $\mathrm{Fe}_{1-\mathrm{x}} \mathrm{Co}_{\mathrm{x}}$ alloys with $\mathrm{x}$ : (a) 0.1 ; (b) 0.2 ; (c) 0.3 ; (d) 0.5 . Values for $\mathrm{Fe}_{0.5} \mathrm{Co}_{0.5}$ are extracted from reference 14.

\subsection{Magnetic and heating properties of the heating agents}

The magnetic properties of the bimetallic NPs have been evaluated by Vibrating Sample Magnetometry (VSM) applying a field up to $3 \mathrm{~T}$ at both $300 \mathrm{~K}$ and $5 \mathrm{~K}$ (Figure 3). Magnetization as a function of applied field curves for Fe-NPs and FeC-NPs are not shown, as they are in good agreement with the previously published ones. The evolution of $M_{\mathrm{S}}$ as a function of Co fraction shows that $M_{\mathrm{S}}$ increases with Co content up to a concentration of $30 \%$ and then decreases when Co concentration is further increased to $50 \%$. The highest $M_{\mathrm{S}}$ value, $245 \pm 5 \mathrm{~A} \cdot \mathrm{m}^{2} \cdot \mathrm{kg}^{-1}$ at $5 \mathrm{~K}$ and $240 \pm 5 \mathrm{~A} \cdot \mathrm{m}_{2} \cdot \mathrm{kg}^{-1}$ at $300 \mathrm{~K}$ (bulk value $245 \mathrm{~A} \cdot \mathrm{m}^{2} \cdot \mathrm{kg}^{-1}$ at $300 \mathrm{~K}$ ) is obtained for $\mathbf{F e}_{0.7} \mathbf{C o}_{0.3}$-NPs and $M_{\mathrm{S}}$ decreases to $228 \pm 5 \mathrm{~A} \cdot \mathrm{m}^{2} \cdot \mathrm{kg}^{-1}$ (5 K) and $225 \mathrm{~A} \cdot \mathrm{m}^{2} \cdot \mathrm{g}^{-1}$ (300 K) for $\mathbf{F e}_{0.5} \mathbf{C o}_{0.5}$-NPs (bulk value $232 \mathrm{~A} \cdot \mathrm{m}^{2} \cdot \mathrm{kg}^{-1}$ at $300 \mathrm{~K}$ ), in good agreement with bulk values and indicating the absence of oxidation of the samples (Table 2). ${ }^{28}$ The coercive field values 
decrease monotonically with the increase of Co content, from $17.5 \mathrm{mT}$ for $\mathbf{F e}_{0.9} \mathbf{C o}_{0.1}$-NPs to 10 mT for $\mathbf{F e}_{0.5} \mathbf{C o}_{0.5}$-NPs (5 K). This decrease could be related to a change in the MNP size or of their anisotropy. Literature data indicate that the anisotropy of the bulk alloy decreases when adding Co for concentrations in the range [0-40\%] and slightly increases again in the range [4050\%] (29). Moreover, as shown Table 1 MNP size decreases when increasing Co content, especially for the $\mathrm{Fe}_{0.5} \mathrm{Co}_{0.5}$ sample. We thus interpret the decrease of coercive field as resulting from the decrease of both anisotropy and MNP size, even if discriminating between the contribution of the two effects is difficult.

No significant shift $(>2 \mathrm{mT})$ could be observed in the hysteresis cycle at $5 \mathrm{~K}$, hence confirming the absence of oxidation of the NPs. These characteristics are well adapted for the magnetically induced heating using the FeCo NPs-based system. ${ }^{30}$ 

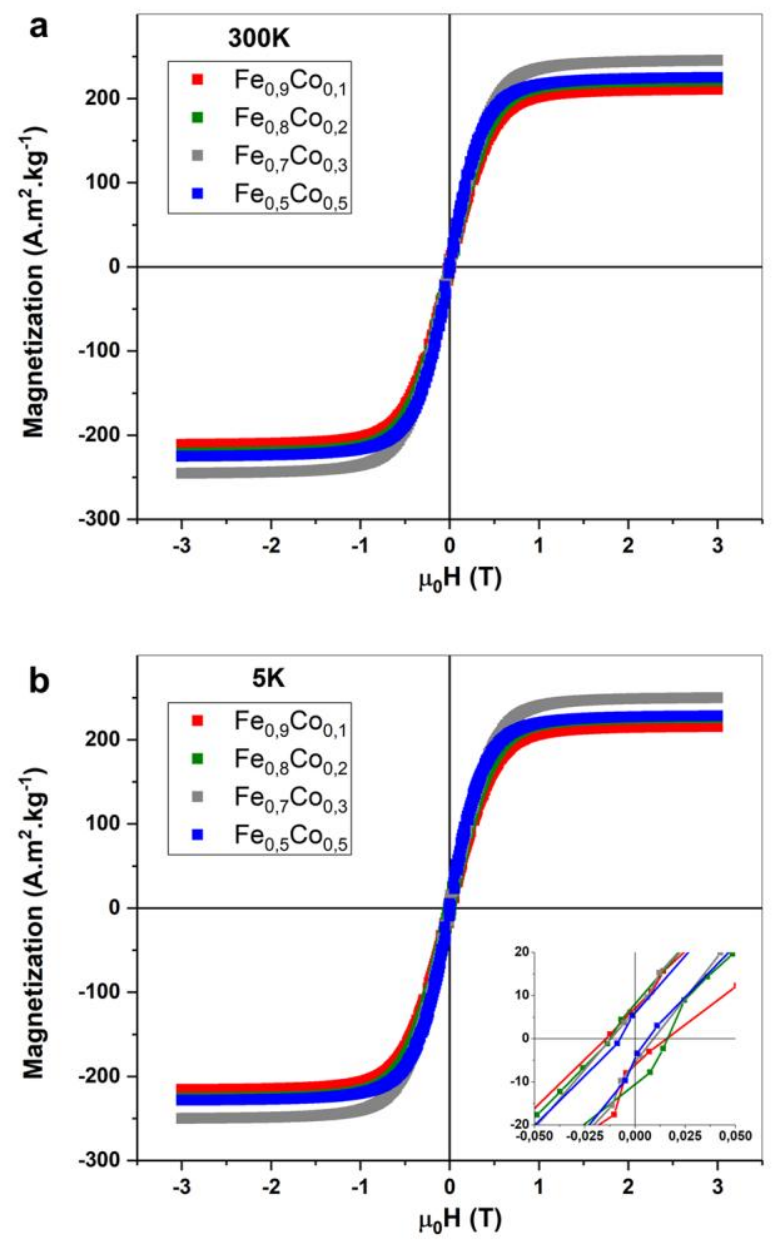

Figure 3. Hysteresis loops of $\mathrm{Fe}_{1-\mathrm{x}} \mathrm{Co}_{\mathrm{x}} \mathrm{NP}$ alloys obtained by VSM measurement at (a) $300 \mathrm{~K}$ and (b) $5 \mathrm{~K}$. 
Table 2. Magnetic and heating properties of $\mathrm{Fe}_{1-\mathrm{x}} \mathrm{Co}_{\mathrm{x}} \mathrm{NP}$ alloys.

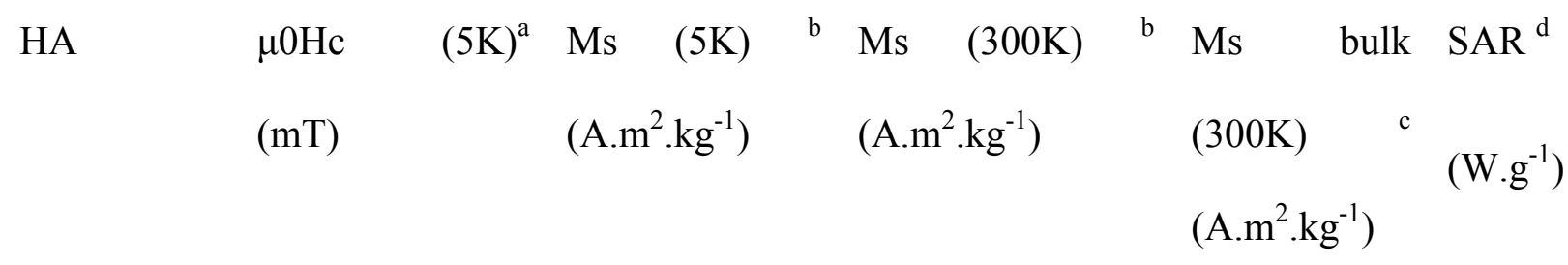

\begin{tabular}{llcccc}
\hline $\mathrm{Fe}_{0.5} \mathrm{Co}_{0.5}$ & 10 & 228 & 225 & 232 & 1650 \\
& & & & & \\
\cline { 2 - 6 } $\mathrm{Fe}_{0.7} \mathrm{Co}_{0.3}$ & 12 & 245 & 240 & 245 & 1260 \\
& & & & & \\
\hline $\mathrm{Fe}_{0.8} \mathrm{Co}_{0.2}$ & 14 & 226 & 221 & 230 & 1140 \\
\hline $\mathrm{Fe}_{0.9} \mathrm{Co}_{0.1}$ & 17.5 & 216 & 211 & 225 & 1000
\end{tabular}

a: Values of coercive fields $\left(\mu_{0} H_{\mathrm{c}} \pm 1,5 \mathrm{mT}\right)$ obtained at $5 \mathrm{~K}$

b: Saturation magnetization $\left(M_{\mathrm{S}} \pm 5 \mathrm{~A} \cdot \mathrm{m}^{2} \cdot \mathrm{kg}^{-1} \mathrm{mT}\right)$ from the hysteresis cycles.

c: Literature data are extracted from reference 28.

d: SAR values are obtained by calorimetry at $47 \mathrm{mT}$ and $100 \mathrm{kHz}$.

The heating properties of the NPs have been assessed by two complementary methods (see Methods for more details): (i) The room temperature SAR values were measured on samples where MNPs are dispersed in a solvent. This is the standard measurement, performed by most groups to evaluate the heating power of MNPs. (ii) The temperature dependence of the SAR, performed on solid-state samples, where the MNPs are dispersed on a catalyst support; this is a non-trivial technic which requires a dedicated setup and specific data analysis.

Room temperature SAR measurements were performed on suspensions in mesitylene upon applying an alternating magnetic field (frequency of $100 \mathrm{kHz}$ ) with a root mean square (rms) amplitude ranging from 0 to $48 \mathrm{mT}$. Results are shown in Figure 4. It has been reported that the heating threshold for FeC-NPs corresponds to an amplitude of $30 \mathrm{mT}$ and that these NPs display 
a remarkably high heating capability at $48 \mathrm{mT}$ (up to $2000 \mathrm{~W} / \mathrm{g}$ ). ${ }^{25}$ On the other hand, Fe-NPs start heating at higher amplitudes $(>35 \mathrm{mT})$ and reach $820 \mathrm{~W} / \mathrm{g}$ at $48 \mathrm{mT}$, while alloying Fe with Co enables heating at $25 \mathrm{mT}$ for $\mathbf{F e}_{0.9} \mathbf{C o}_{0.1}$-NPs, at $20 \mathrm{mT}$ for $\mathbf{F e}_{0.8} \mathbf{C o}_{0.2}-\mathbf{N P s}$ and $\mathbf{F e}_{0.7} \mathbf{C o}_{0.3^{-}}$ NPs, and $15 \mathrm{mT}$ for $\mathbf{F e}_{\mathbf{0}_{.5}} \mathbf{C o}_{0.5}$-NPs. The SAR, measured at $48 \mathrm{mT}$ increases with increasing Co content, and varies from $1000 \mathrm{~W} \cdot \mathrm{g}^{-1}(\mathrm{x}=0.1)$ to $1650 \mathrm{~W} \cdot \mathrm{g}^{-1}(\mathrm{x}=0.5)$ (Figure 4, Table 2). The evolution of the $\operatorname{SAR}\left(\mu_{0} H\right)$ curves when increasing Co concentration is typical of what is expected when decreasing NPs anisotropy. High anisotropy NPs such as the pure iron NPs display a SAR starting to increase at large field and their $\operatorname{SAR}\left(\mu_{0} H\right)$ curve has a moderate slope. At the opposite, low anisotropy NPs such as the $\mathrm{Fe}_{0.5} \mathrm{Co}_{0.5}$ display a SAR starting to increase at low field and their $\operatorname{SAR}\left(\mu_{0} H\right)$ has a higher slope. If these MNPs were measured at very high field, the high-anisotropy NPs would have a much larger SAR than the low-anisotropy ones. However, in the present case, the various applied magnetic fields are smaller than the coercive field of the high-anisotropy NPs. Therefore, the high anisotropy NPs display a SAR smaller than the low-anisotropy NPs. A similar behavior has been previously observed ${ }^{31}$, when measuring the heating properties of NPs with variable anisotropies. 


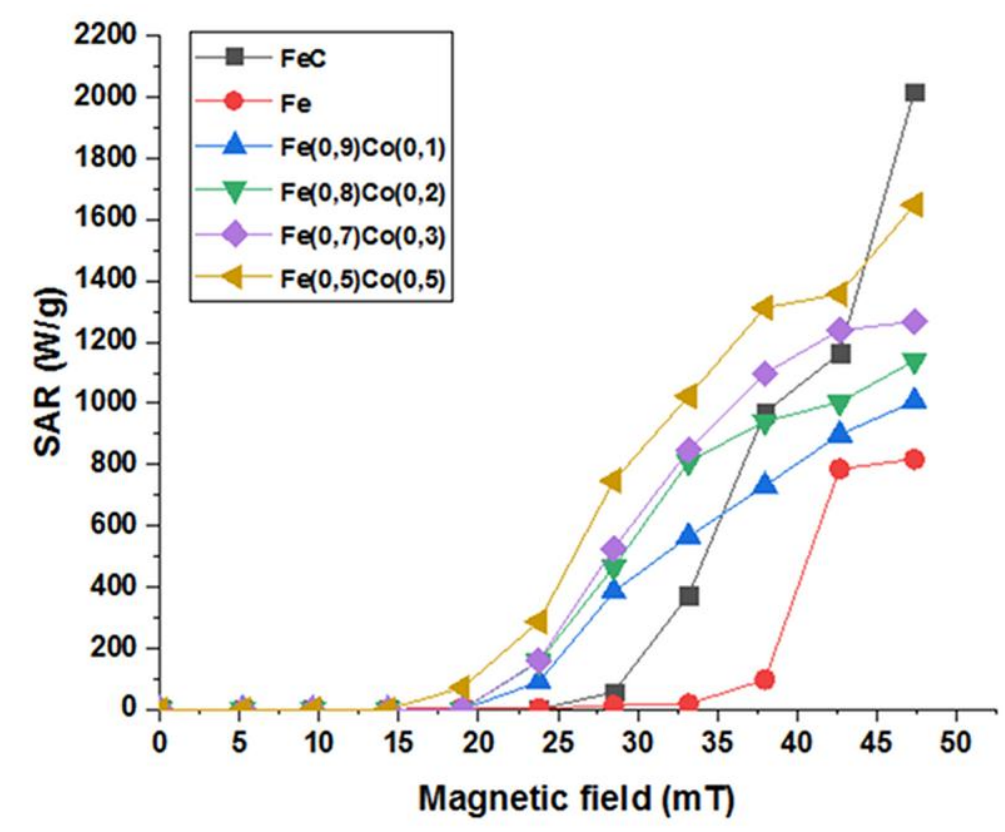

Figure 4. SAR of the different magnetic NHAs, suspended in mesitylene, measured by calorimetry, $\mu_{0} H_{\mathrm{rms}}=0-48 \mathrm{mT}, \mathrm{f}=100 \mathrm{kHz}$.

As a second method, and in order to be as close as possible to the conditions of the catalytic tests, we have measured the temperature dependence of the SAR of the $\mathbf{F e}_{\mathbf{x}} \mathbf{C o}_{1-\mathbf{x}}-\mathbf{N P s}$ and the FeC-NPs. supported on Silica-Alumina support (SiRAlOx-5C) at 10 wt.\% loadings, at different fields and at a frequency of $300 \mathrm{kHz}$. We have measured the temperature dependence of the SAR for the $\mathbf{F e}_{\mathbf{x}} \mathbf{C o}_{1-\mathbf{x}}-\mathbf{N P s}$ and the FeC-NPs (see experimental part for details). The temperatures reached during these experiments depend not only on the NPs composition but also on the amount of sample used, and on the heat losses of the calorimeter. We have performed experiments up to $400^{\circ} \mathrm{C}$. This steady state temperature is lower than the one reached during catalysis (see below) due to a lower mass of sample used for the SAR measurements. The heating properties are not stable and evolve when the samples reach a temperature around $200^{\circ} \mathrm{C}$ (see Supporting Information Fig. S3 and Fig. S4 for details). We attribute this effect to an agglomeration of the nanoparticles similar to what is observed during the catalytic tests (see 
below and Supporting Information Figure S5). This evolution occurs for all samples except for the FeC-NPs. After this initial structural evolution, the heating properties remain stable and reproducible. In Figure 5, we show the SAR properties of the different samples at a field of 65 $\mathrm{mT}$, as structural changes occur at higher fields. Thus, these heating properties can be considered as representative of the ones displayed by the samples under catalysis conditions.

As observed in Figure 5, the SAR absolute values of the NPs display two different types of behavior. The low-temperature SAR of FeC-NP, $\mathbf{F e}_{0.9} \mathbf{C o}_{0.1}-\mathbf{N P}$ and $\mathbf{F e}_{0.5} \mathbf{C o}_{0.5}-\mathbf{N P}$ ranges from 120 to $280 \mathrm{~W} / \mathrm{g}$, whereas the one of $\mathbf{F e}_{0.8} \mathbf{C o}_{0.2}-\mathbf{N P}$ and $\mathbf{F e}_{0.7} \mathbf{C o}_{0.3}-\mathbf{N P}$ displays values similar to those measured in suspension, ranging from 1100 to $1465 \mathrm{~W} / \mathrm{g}$. In these latter samples, it could be observed with the naked eye that, as in suspension, the NPs formed macroscopic chains under the high frequency magnetic field, which demonstrates that these NPs were not efficiently immobilized on the SiRA1Ox-5@ (See Supporting Information Figure S5). This observation is a further demonstration of the importance of chains for the heating properties of NPs. ${ }^{28,31}$

Nevertheless, the SAR decreases with temperature for all samples and independently of any aggregation or chain formation. Figure 5(a) shows that $\mathbf{F e}_{0.9} \mathbf{C o}_{0.1}-\mathbf{N P s}$ and $\mathbf{F e}_{0.5} \mathbf{C o}_{0.5}-\mathbf{N P s}$ have a higher SAR than FeC-NPs.
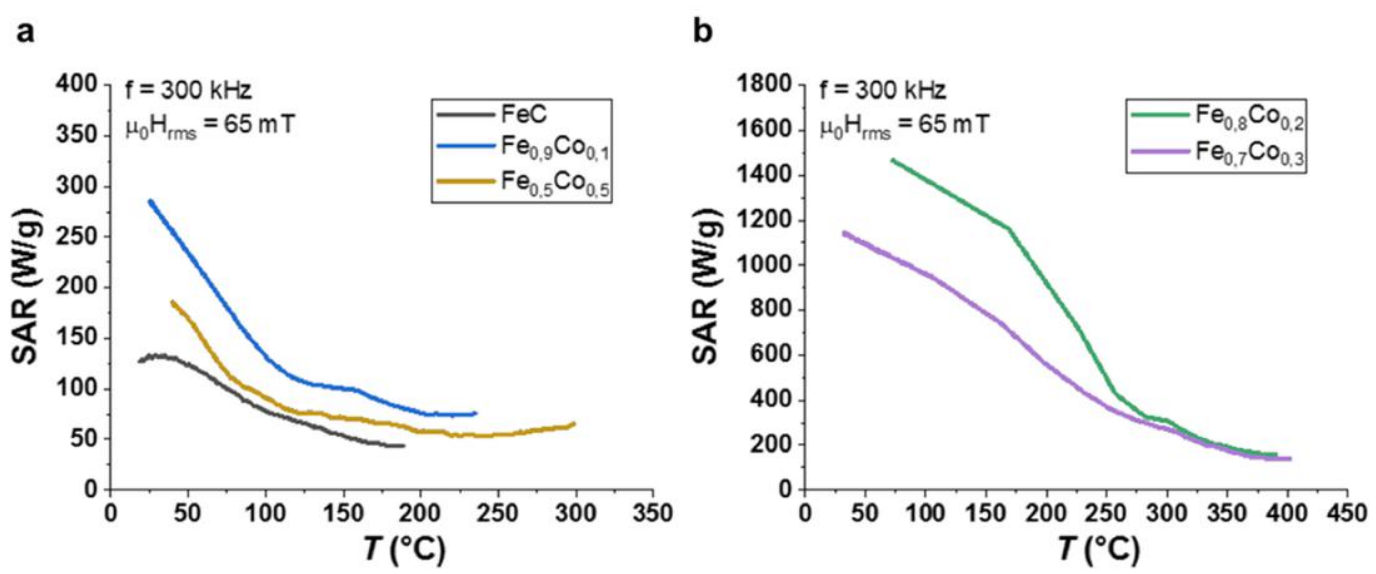
Figure 5. Temperature dependence of the SAR of $\mathbf{F e}_{\mathbf{x}} \mathbf{C o} \mathbf{o}_{1-\mathbf{x}}-\mathbf{N P}$ and FeC-NP supported on Siralox-5(C) at 10wt $\%$ under a field of amplitude $\mu_{0} H_{\mathrm{rms}}=65 \mathrm{mT}$ at $f=300 \mathrm{kHz}$.

Overall, it has been shown by Mössbauer, VSM and SAR measurements that the progressive addition of Co in Fe-based NPs leads to a coherent modification of the composition of the system and changes their heating power. FeC-NPs present a very high value of SAR $(2000 \mathrm{~W} / \mathrm{g}$ at 48 $\mathrm{mT}, 100 \mathrm{kHz}$ ) when measured in suspension, but this material is expected to have a too low $T_{\mathrm{C}}$ to perform catalysis at high temperature. On the other hand, alloying Fe-NPs with progressive increase of the Co fraction enables to progressively increase their $T_{\mathrm{C}}$ and thus, their ability to activate catalysis at higher temperatures. This study shows for the first time that the temperature dependence of the SAR must be considered when designing performant catalytic systems. We have chosen to pursue our study with $\mathbf{F e}_{\mathbf{0 . 5}} \mathbf{C o}_{0.5}$ NPs because: i) Figure 4 indicates that a lower magnetic field is required at room temperature to generate significant heating and ii) $\mathbf{F e}_{\mathbf{0 . 5}} \mathbf{C o}_{\mathbf{0 . 5}}$ NPs $T_{\mathrm{C}}$ is expected to be high from the literature. In this context we have first explored the potential of $\mathbf{F e}_{\mathbf{0 . 5}} \mathbf{C o}_{\mathbf{0 . 5}}$-NPs in $\mathrm{CO}_{2}$ hydrogenation in comparison to $\mathbf{F e C}-\mathbf{N P s}$.

\section{Use of the $\mathrm{Fe}_{0.5} \mathrm{Co}_{0.5} \mathrm{NPs}$ in catalysis}

\section{1 $\mathrm{Fe}_{0.5} \mathrm{Co}_{0.5}$-NPs as heating agent for the Sabatier reaction}

In a previous work, we showed that $\mathrm{CO}_{2}$ hydrogenation known as the Sabatier reaction could be performed with a $\mathrm{CH}_{4}$ yield exceeding $80 \%$ for rms field amplitudes above $25 \mathrm{mT}$ at $300 \mathrm{kHz}$ using FeC-NPs displaying high heating power $(2000 \mathrm{~W} / \mathrm{g})$, and associated with Ni or Ru NPs deposited on SiRAlOx-5C as catalysts. ${ }^{7}$ This reaction is exothermic and does not require high 
temperatures $\left(300-350^{\circ} \mathrm{C}\right){ }^{32}$ therefore, FeC-NPs displaying low Curie temperature were very efficient.

In the present work, we used as a catalyst $10 \mathrm{wt} \% \mathrm{Ni}$ NPs supported on SiRAlOx-5® on which $4.3 \mathrm{wt} \% \mathbf{F e}_{0.5} \mathbf{C o}_{0.5}$-NPs were added as NHAs. The Ni catalyst was prepared by decomposition of $\mathrm{Ni}(\mathrm{COD})_{2}$ under inert atmosphere (see Methods Section). ${ }^{15}$ We performed the Sabatier reaction under continuous flow with a $\mathrm{CO}_{2}: \mathrm{H}_{2}$ ratio of $1: 4$ and a total flow of $25 \mathrm{~mL} \cdot \mathrm{min}^{-1} \cdot \mathrm{CO}_{2}$ conversion reached $83.5 \%$ with $92.2 \%$ selectivity for $\mathrm{CH}_{4}$ at $47 \mathrm{mT}, 300 \mathrm{kHz}$, which is as good as the previously published results using Ru NPs. The catalyst has been observed by TEM before and after $5 \mathrm{~h}$ time on stream (TOS) evidencing a moderate increase of $\mathbf{F e}_{0.5} \mathbf{C o}_{0.5}$-NPs size (up to $40 \mathrm{~nm}$ ) due to sintering, but no major instability of the system could be detected (see Fig. S6). Moreover, we tested the activation of the Sabatier reaction at lower frequencies. Using the same sample but reducing the frequency to $100 \mathrm{kHz}$, without changing the amplitude (47 mT), the catalytic performances decreased dramatically, but they could be restored $\left(92.5 \% \mathrm{CO}_{2}\right.$ conversion, $90 \% \mathrm{CH}_{4}$ selectivity) by increasing the FeCo NHAs loading up to $10.5 \mathrm{wt} \%$. The frequency of the field has then been decreased down to $50 \mathrm{kHz}$ (at $47 \mathrm{mT}$ ), but this completely suppressed the catalytic activity, and in this case an increase of FeCo NHAs loading (15 wt $\%$ ) could not restore the activity. The catalytic performances in Sabatier reaction using $\mathbf{F e}_{0.5} \mathbf{C o}_{0.5^{-}}$ NPs are presented in Table 3. Thus, for the Sabatier reaction, without any further optimization, using $\mathrm{Fe}_{0.5} \mathrm{Co}_{0.5}$-NPs enables to equal the performances reached by using $\mathbf{F e C - N P s}$ while decreasing the magnetic field frequency from $300 \mathrm{kHz}$ down to $100 \mathrm{kHz}$.

\section{$2.2 \mathrm{Fe}_{0.5} \mathrm{Co}_{0.5}$-NPs as NHAs for high temperature magnetically induced catalysis}


In order to demonstrate the possibility for the system to operate at higher temperatures, we employed the $\mathbf{F e}_{\mathbf{0 . 5}} \mathbf{C o}_{0.5}$-NPs in endothermic catalytic reactions operating above $350^{\circ} \mathrm{C}$. In this respect, we considered Ni-catalyzed dry reforming of propane (PDR) and of methane (MDR), which require temperatures in the range $550-700^{\circ} \mathrm{C}$ and $600-900^{\circ} \mathrm{C}$ respectively. We also investigated propane dehydrogenation $(\mathrm{PDH})$ requiring temperatures above $700^{\circ} \mathrm{C}$, using new Ptbased nanoparticles as catalysts. It has to be noted that no attempt was made to optimize these reactions (catalyst and catalytic bed composition, operation conditions), since in a first step we intend to establish a proof-of-concept concerning the temperatures attained in the reactor rather than to develop a process.

\subsubsection{Dry reforming of light alkanes using $\mathrm{Fe}_{0.5} \mathrm{Co}_{0.5}$-NPs as NHAs}

Methane dry reforming (MDR) and propane dry reforming (PDR) are both highly endothermic reactions : $\Delta \mathrm{H}_{300 \mathrm{~K}, \mathrm{MDR}}=247 \mathrm{~kJ} / \mathrm{mol}, \Delta \mathrm{H}_{300 \mathrm{~K}}, \mathrm{PDR}=620 \mathrm{~kJ} / \mathrm{mol}$ and require temperatures in the range of $600-900^{\circ} \mathrm{C}(\mathrm{MDR})^{33}$ and between 550 and $700^{\circ} \mathrm{C}(\mathrm{PDR}) .^{34} \mathrm{Ni}$-based catalysts are generally used to perform dry reforming reactions with yields for CO between $60 \%$ and $80 \%$ depending on the support and the temperature range. ${ }^{35,36}$ Here, for the preparation of the PDR and MDR catalysts, $10 \mathrm{wt} \%$ of Ni NPs, resulting from the decomposition of $\mathrm{Ni}(\mathrm{COD})_{2}$ under hydrogen, have been impregnated on SiRAlOx-5C. $10 \mathrm{wt} \%$ of $\mathbf{F e}_{\mathbf{0 . 5}} \mathbf{C o}_{\mathbf{0 . 5}}-\mathbf{N P s}$ have then been incorporated to the Ni/SiRAlOx-5C catalyst (see Experimental Section for details). The gas flows were $30 \mathrm{~mL} \cdot \mathrm{min}^{-1}$ for $\mathrm{CO}_{2}$ and $10 \mathrm{~mL} \cdot \mathrm{min}^{-1}$ for $\mathrm{C}_{3} \mathrm{H}_{8}$, for PDR and $10 \mathrm{~mL} \cdot \mathrm{min}^{-1}$ for $\mathrm{CH}_{4}$, and $10 \mathrm{~mL} \cdot \mathrm{min}^{-1}$ for $\mathrm{CO}_{2}$ for MDR respectively. In the case of PDR, conversion of propane up to $66.8 \%$ has been achieved with $54.6 \%$ selectivity to $\mathrm{CO}$ at $44 \mathrm{mT}, 300 \mathrm{KHz}$. Interestingly at 53 $\mathrm{mT}(300 \mathrm{KHs})$ a conversion of $81.5 \%$ was achieved with a CO selectivity of $61.5 \%$. For MDR, a methane conversion of $11 \%$ was observed under the same conditions. It has to be noted that the 
selectivity toward $\mathrm{CO}$ is lower in the case of propane dry reforming due to the simultaneous reaction between $\mathrm{CO}$ and $\mathrm{H}_{2}$, both produced in the reaction, leading to nearly $50 \%$ conversion of $\mathrm{CO}$ into $\mathrm{CH}_{4}$ (see gas chromatogram in Fig. S7). This certainly occurs in the case of MDR but is interpreted as a lower conversion value. These results show the capability of $\mathbf{F e}_{0.5} \mathbf{C o}_{0.5}-\mathbf{N P s}$ to reach temperatures, high enough to activate highly endothermic reactions (Table 3). 
Table 3. Summary of the catalytic data obtained for the Sabatier reaction, PDR, and MDR using $\mathrm{Fe}_{\mathbf{0 . 5}} \mathrm{Co}_{0.5}$-NPs as heating agent.

\begin{tabular}{|c|c|c|c|c|c|c|c|}
\hline Reaction & $\begin{array}{l}\text { HA } \\
\text { loading } \\
(\% w t)\end{array}$ & $\begin{array}{l}\text { Catalyst } \\
\text { loading } \\
(\% w t)\end{array}$ & $\begin{array}{l}\text { Field } \\
\text { frequency } \\
(\mathrm{kHz})\end{array}$ & $\begin{array}{l}\text { Field } \\
\text { amplitude } \\
(\mathrm{mT})\end{array}$ & $\begin{array}{l}\text { Conversion } \\
\% \mathrm{X}\end{array}$ & $\begin{array}{l}\text { Selectivity } \\
\% \mathrm{~S}\end{array}$ & $\begin{array}{l}\mathrm{T}_{\text {bulk }}{ }^{\mathrm{a}} \\
\left({ }^{\circ} \mathrm{C}\right)\end{array}$ \\
\hline \multirow[t]{6}{*}{ Sabatier } & & & & & $\mathrm{X}\left(\mathrm{CH}_{4}\right)$ & $\mathrm{S}\left(\mathrm{CH}_{4}\right)$ & \\
\hline & 4.3 & 10 & 300 & 47 & 83.5 & 92.2 & \\
\hline & 4.3 & & 100 & & 3.2 & 100 & \\
\hline & 10.5 & & 100 & & 92.5 & 90 & \\
\hline & 10.5 & & 50 & & 0 & 0 & \\
\hline & 15 & & 50 & & 1 & 100 & \\
\hline $\mathrm{FeC}(\operatorname{ref} 15)$ & 9 & 7 & 300 & 47 & 87 & 100 & \\
\hline \multirow[t]{4}{*}{ PDR } & & & & & $\mathrm{X}\left(\mathrm{C}_{3} \mathrm{H}_{8}\right)$ & $\mathrm{S}(\mathrm{CO})$ & \\
\hline & 10 & 10 & 300 & 44 & 66.8 & 54.6 & 350 \\
\hline & & & & 53 & 81.5 & 61.5 & 360 \\
\hline & & & & 60 & 100 & 42.8 & $550+^{i}$ \\
\hline \multirow[t]{3}{*}{ MDR } & & & & & $\mathrm{X}\left(\mathrm{CH}_{4}\right)$ & $\mathrm{S}(\mathrm{CO})$ & \\
\hline & 10 & & & 44 & 11 & 100 & 411 \\
\hline & & & & 60 & 9.7 & 100 & $650+^{i}$ \\
\hline
\end{tabular}

a: Temperature is monitored by an IR camera. 


\subsubsection{Propane dehydrogenation using $\mathrm{Fe}_{0.5} \mathrm{Co}_{0.5}-\mathrm{NPs}$ as NHAs}

Since dry reforming of light alkanes could be successfully achieved using $\mathbf{F e}_{0.5} \mathbf{C o}_{0.5}-\mathbf{N P s}$, we decided to attempt propane thermal dehydrogenation $(\mathrm{PDH})$ to prove that using FeCo NHAs with high $T_{\mathrm{C}}$ enables to activate high temperature catalysis. The catalytic dehydrogenation of alkanes such as propane (PDH) has received much attention because of the growing demand for light olefins. ${ }^{34}$ It is an endothermic reaction $\left(\Delta \mathrm{H}_{300 \mathrm{~K}}, \mathrm{PDH}=124 \mathrm{~kJ} / \mathrm{mol}\right)$ taking place at temperatures above $700^{\circ} \mathrm{C}$ and is limited by thermodynamics to up to $30 \%$ conversion and selectivity up to $95 \%$ to propene depending on the catalyst, generally Pt-based ones. Regarding the selectivity for propylene, modification of the catalyst by poisoning Pt sites with Sn allows avoiding side reactions such as hydrogenolysis or cracking. ${ }^{37}$ Propane thermal dehydrogenation $(\mathrm{PDH})$ is generally operated above $700^{\circ} \mathrm{C}$ therefore, its activation constitutes a good temperature indicator. The excellent selectivity for propene reported in the literature using a $\mathrm{PtSn}_{2.5}$ alloy $(0.5 \mathrm{wt} \% \mathrm{Pt}, 0.75 \mathrm{wt} \% \mathrm{Sn})$ incited us to target this same composition. ${ }^{38,39}$ For this purpose we elaborated PtSn NPs by a new organometallic synthesis reaction. First, we prepared Pt nanoparticles (Pt-NPs) in solution by decomposition of $\mathrm{Pt}_{2}(\mathrm{dba})_{3}$ under CO. PtSn nanoparticles were then prepared by adding $\mathrm{Bu}_{3} \mathrm{SnH}$ in the suspension of Pt-NPs, followed by impregnation on SiRAlOx-5@ (0.5 w\% loading). This method allowed the formation of monodisperse PtSn-NPs $(1.4 \pm 0.3 \mathrm{~nm})$ as observed by high-resolution microscopy (Fig. S8). ICP analysis of the supported catalyst revealed the presence of $\mathrm{PtSn}_{3.7}$ and $\mathrm{PtSn}_{3.3}$ alloys in two distinct samples, showing good reproducibility and higher content in Sn than expected (Table S3). Despite the difference between the targeted and the obtained composition, this catalyst has been used in this study. In Fig. S8 we present the PtSn-NPs characteristics and the detailed catalytic results obtained with PtSn-NPs with $\mathbf{F e}_{0.5} \mathbf{C o}_{0.5}-\mathbf{N P s}$ as a NHAs are presented in Table S4. $10 \mathrm{wt} \%$ of $\mathbf{F e}_{0.5} \mathbf{C o}_{0.5}-\mathbf{N P s}$ 
were mixed with the supported PtSn-NPs by wet impregnation. No heat treatment neither reduction step prior to testing were necessary, since the whole procedure was performed under inert conditions.

This catalyst has been tested for PDH with a pure propane flow of $20 \mathrm{~mL} \cdot \mathrm{min}^{-1}$. At $44 \mathrm{mT}, 300$ $\mathrm{kHz}, 17,5 \%$ of the incoming propane could be converted, with a selectivity to propene up to 77.3\%. Despite the non-optimized performances of this system, this result constitutes an additional proof that $\mathbf{F e}_{0.5} \mathbf{C o}_{0.5}$-NPs can successfully perform catalysis at high temperatures. The catalytic results are shown in Figure 6 and gas chromatograms can be found in Fig. S9.

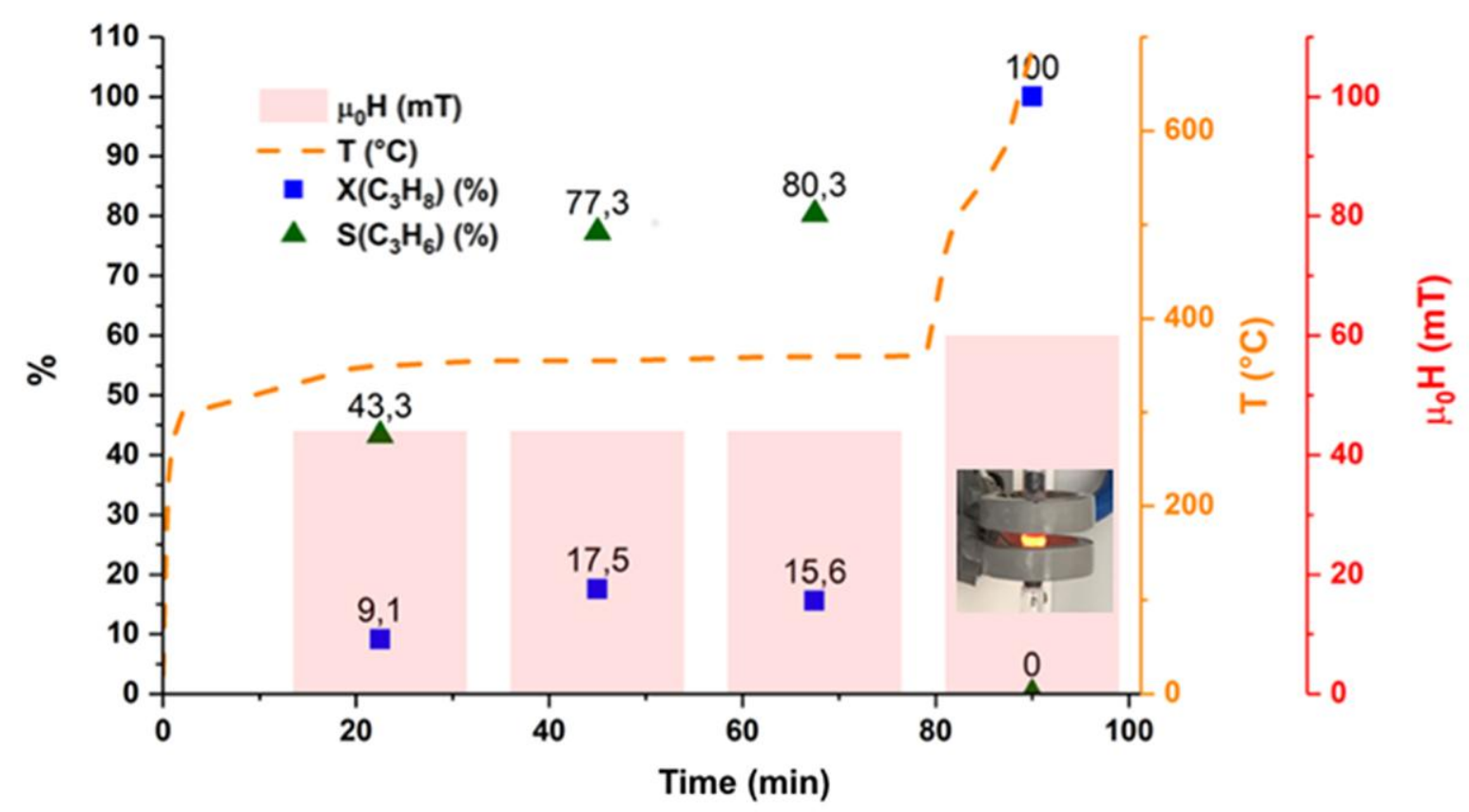

Figure 6. Catalytic performances of $\mathbf{F e}_{0.5} \mathbf{C o}_{0.5}-\mathrm{NPs}$, PtSn- Siralox-5@ under magnetic induction $(300 \mathrm{kHz})$ and pure propane flow, $20 \mathrm{~mL} \cdot \mathrm{min}^{-1}$.

\subsubsection{Comparison of the NHAs in propane dehydrogenation}


As a final demonstration that the $\mathbf{F e}_{0.5} \mathbf{C o}_{0.5}$ composition is optimal for high-temperature catalysis, $10 \mathrm{wt} \%$ of all synthesized $\mathrm{Fe}_{\mathrm{x}} \mathrm{Co}_{1-\mathrm{x}} \mathrm{NHAs}$ were mixed with the supported PtSn catalyst by wet impregnation. The catalysts were then tested in the PDH under the same conditions as above. The catalytic results are shown in Figure 7. The temperature of the systems has been determined by an IR camera which was monitoring the temperature of the reactor wall, thus, largely underestimating the temperature of the catalyst. The as-obtained temperature values are however, a good relative indicator of the differences between the catalysts tested. Interestingly, the propene yield profile follows approximately the temperature profile recorded, confirming what is already known about this reaction when activated by conventional heating. Figure 7 shows that the global trend of temperature attained in the system follows the Co content in the NHAs, the best mean yield (10\%) being hence achieved by using $\mathbf{F e}_{\mathbf{0 . 5}} \mathbf{C o}_{\mathbf{0 . 5}}$-NPs, which reaches the highest temperature $\left(350^{\circ} \mathrm{C}\right.$ by IR camera) in the system at $44 \mathrm{mT}, 300 \mathrm{kHz}$.

The detailed results obtained with the other NHAs are presented in Table S4. This study demonstrates that, despite their SAR being in the same range as the one of $\mathbf{F e}_{\mathbf{x}} \mathbf{C o}_{1-\mathbf{x}}$ alloys, $\mathbf{F e C}$ NPs cannot heat enough under magnetic induction to perform catalysis above $400^{\circ} \mathrm{C}$ due to a limitation imposed by their $T_{\mathrm{C}}$, while $\mathbf{F e}_{\mathbf{0 . 5}} \mathbf{C o}_{0.5}$-NPs enable to activate successfully DR of light alkanes as well as PDH. This result clearly highlights the interest of the incorporation of Co in the NHAs up to a 50/50 composition for obtaining nanoparticles displaying both a large $T_{\mathrm{C}}$ and SAR, appropriate for high temperature magnetically activated catalysis. 


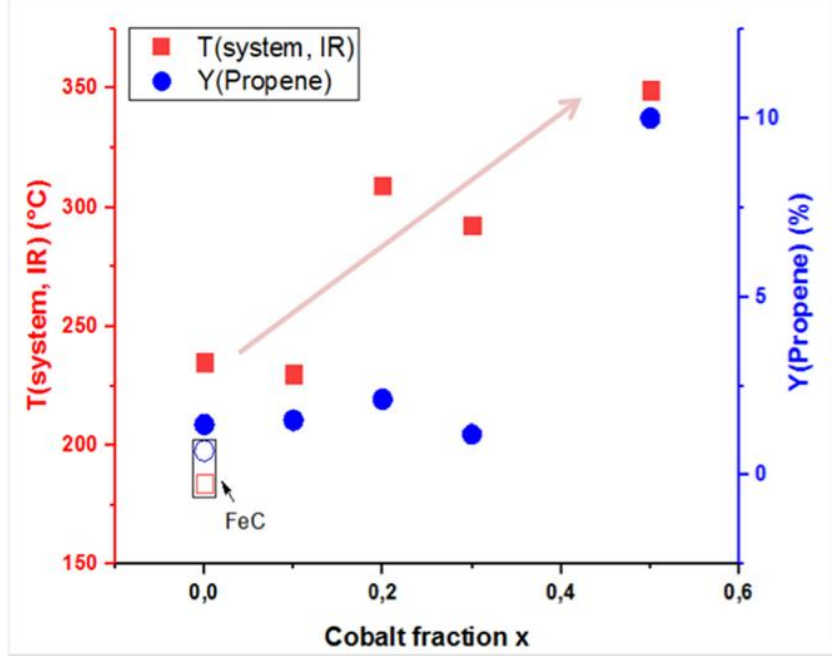

Figure 7. Catalytic results of propane dehydrogenation using different NHAs as a function of the Co fraction $x$ in $\mathrm{Fe}_{1-\mathrm{x}} \mathrm{Co}_{\mathrm{x}}$ in full marks. Empty marks correspond to FeC-NPs. The yield in propene ( $Y$ propene) was calculated as the conversion of propane multiplied by the selectivity toward propene (blue, right axis). The temperature, monitored by IR camera is shown on the left axis (red). The red arrow is a guide for the eye. Each value of yield and temperature is averaged over 3 injections.

\subsubsection{System stability}

In order to reach at even higher temperatures and thus, better performances, the magnetic field rms amplitude has been increased up to $60 \mathrm{mT}$ at $300 \mathrm{kHz}$. PDR could be performed with 100\% conversion of propane $(66.8 \%$ at $44 \mathrm{mT})$ with $42.8 \%$ of selectivity for $\mathrm{CO}(54.6 \%$ at $44 \mathrm{mT})$ while conversion of methane in the case of MDR decreased from $11 \%$ to $9.7 \%$, most likely due to the possible deactivation of the catalyst through deposition of carbon. While the temperature of the system appears stable at $44 \mathrm{mT}, 300 \mathrm{kHz}$, a progressive increase of the temperature could be observed at $60 \mathrm{mT}$. The same observation could be made in the case of PDH, in which, when the field amplitude increases from $44 \mathrm{mT}$ to $60 \mathrm{mT}$, a dramatic and abrupt temperature increase 
takes place (Figure 6). Indeed, a few minutes after the field application, the temperature measured showed values higher than $800^{\circ} \mathrm{C}$ and an intense red flashlight and overpressure in the reactor imposed stopping of the reaction. TEM observation of the catalyst after reaction revealed that $\mathbf{F e}_{0.5} \mathbf{C o}_{0.5}$-NPs had suffered extensive sintering to reach sizes over $500 \mathrm{~nm}$ (Figure 8).

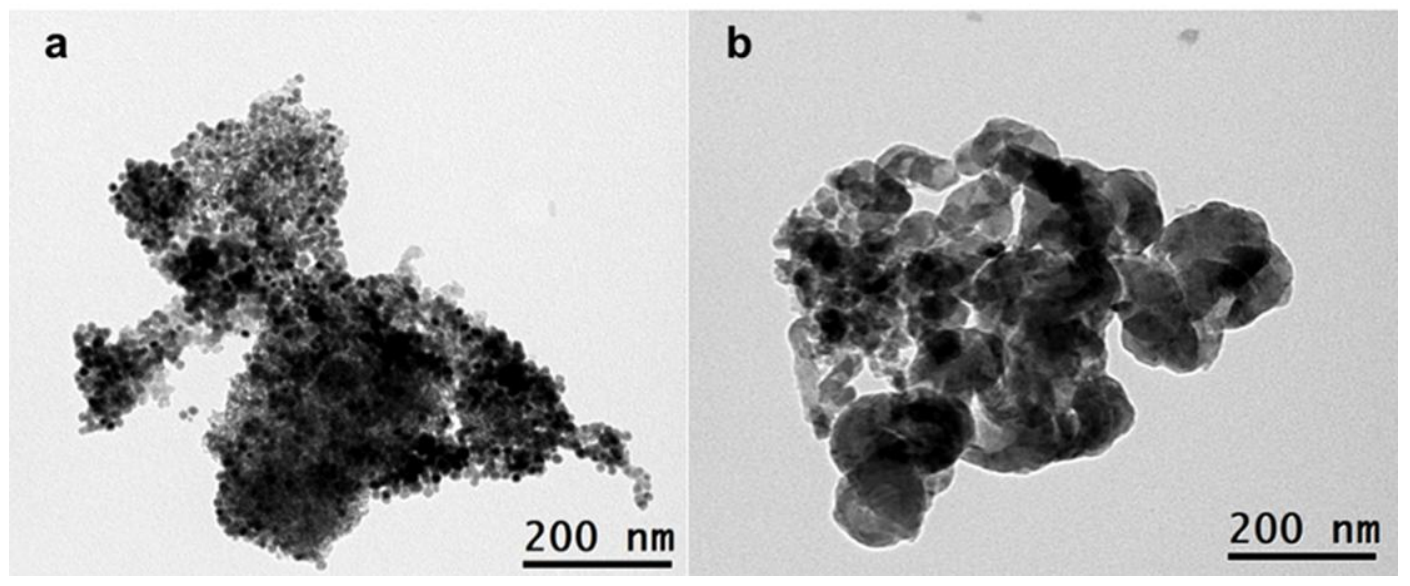

Figure 8. TEM observation of $10 \mathrm{wt} \% \mathbf{F e}_{0.5} \mathbf{C o}_{0.5}$ NHAs loaded on Pt $0.5 w t \%$, Sn $0.75 w t \%$ Siralox-5(C) (a) as prepared and (b) after $1.5 \mathrm{~h}$ TOS under PDH conditions at $44 \mathrm{mT}, 300 \mathrm{kHz}$, for (1h), followed by $30 \mathrm{~min}$ at $60 \mathrm{mT}$.

These results incited us to follow the evolution of our catalysts under the initially tested less drastic conditions, taking the $\mathrm{PDH}$ case as a representative example.

\subsubsection{1 $\quad \mathrm{Fe}_{0.5} \mathrm{Co}_{0.5}$-NPs sintering}

Three samples of the same catalyst composed of $10 \mathrm{wt} \% \mathbf{F e}_{0.5} \mathbf{C o}_{0.5}-\mathbf{N P s}, 0.5 \mathrm{wt} \% \mathrm{Pt}$ and $0.75 \mathrm{wt} \%$ Sn on SiRA1Ox-5 $\odot$ have been observed by EDX. The first corresponds to the asprepared catalyst. Two samples were magnetically activated using a field $\mu_{0} H_{\mathrm{rms}}=44 \mathrm{mT}$ at 300 $\mathrm{kHz}$ under propane flow $(20 \mathrm{~mL} / \mathrm{min})$ and observed after $1.5 \mathrm{~h}$ and $3.5 \mathrm{~h}$ TOS. EDX mapping revealed that $\mathbf{F e}_{0.5} \mathbf{C o}_{0.5}$-NPs were indeed sintered even at $44 \mathrm{mT}$, and their mean size increased 
with time from $10.6 \mathrm{~nm}$ to $15.5 \mathrm{~nm}$ after $1.5 \mathrm{~h}$ ) and to $53.6 \mathrm{~nm}$ (after $3.5 \mathrm{~h}$ ) (Figure 9). The PtSnNPs, due to their small size and low loading, could not be easily identified by EDX mapping. However, after $3.5 \mathrm{~h}$, Pt and Sn could be detected at the same location as $\mathbf{F e}_{0.5} \mathbf{C o}_{0.5}$ - $\mathbf{N P s}$ indicating that the catalyst composition had been modified. This observation is in good agreement with previous observations in traditional heterogeneous catalysis. ${ }^{40}$
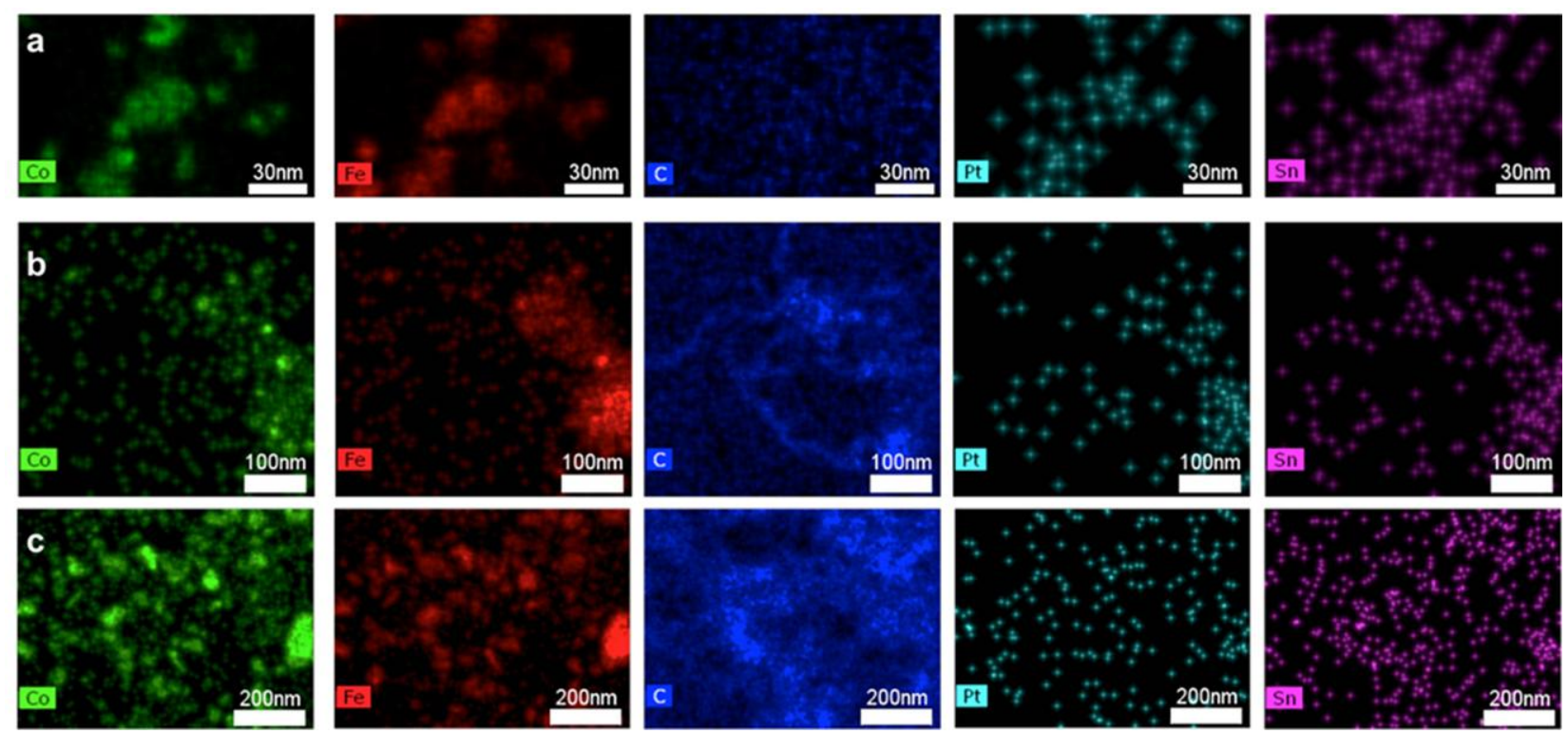

Figure 9. EDX observation of $\mathbf{F e}_{0.5} \mathbf{C o}_{0.5}$-NPs and PtSn-NPs supported on Siralox-5: (a) asprepared catalyst; b) and c) under propane flow and magnetic activation $1.5 \mathrm{~h}$ and $3.5 \mathrm{~h}$ TOS respectively.

It can also be seen from the carbon signal in Figure 9 that carbon has been deposited after $1.5 \mathrm{~h}$ of reaction and its amount is increased after $3.5 \mathrm{~h}$ TOS. Solid carbon has been identified as a catalyst poison leading to a complete deactivation by coke formation. ${ }^{41}$ Under magnetic induction, carbon deposition could be observed at $300 \mathrm{kHz}$ at both $44 \mathrm{mT}$ and $60 \mathrm{mT}$. We therefore believe that under magnetic heating, this reaction leads to the deactivation of our catalyst, as carbon is deposited on the HA but also on the catalyst particles. 


\section{CONCLUSION}

In this work, we report a proof of concept for controlling the temperature of magnetically heated catalytic reactions by increasing the Curie temperature of the heating nanomaterials. We successfully synthesized a series of $\mathrm{Fe}_{1-\mathrm{x}} \mathrm{Co}_{\mathrm{x}}$ alloy NPs of controlled stoichiometries. The bimetallic NPs display an increase in magnetization and decrease in coercivity compared to $\mathrm{Fe}(0)$ NPs. Their SAR increases with increasing Co content and thanks to their higher Curie temperature they are suitable for adjustable heating of catalytic reactions, by modulation of the magnetic field.

$\mathrm{Fe}_{0.5} \mathrm{Co}_{0.5}$ NHAs associated to a Ni/Siralox-5(C) catalyst lead to similar conversion and selectivity for methane production as $\mathrm{FeC} / \mathrm{RuSirAlOx}$ catalysts for the Sabatier reaction, even when decreasing the frequency of the alternating magnetic field or upon reducing the magnetic field amplitude, therefore, they operate with a better energy efficiency. The $\mathrm{Fe}_{0.5} \mathrm{Co}_{0.5}$ particles have also been used successfully to activate reactions that require much higher temperatures such as dry reforming of both propane and methane and even propane dehydrogenation, a challenging reaction of very high industrial interest. This could not be achieved using magnetic materials displaying lower $T_{\mathrm{C}}$, e.g. FeC NPs. Thus, FeCo NHAs of high $T_{\mathrm{C}}$ and high SAR are advantageous for both medium and high temperature reactions. However, two major issues have been identified as needing improvement: the sintering of the $\mathrm{Fe}_{0.5} \mathrm{Co}_{0.5} \mathrm{NPs}$, and carbon deposition leading to catalyst deactivation. As a perspective, the encapsulation of the metal NPs into materials with strong metal-support-interactions could be an option to prevent these 
drawbacks. Further work is in progress to obtain stable systems for high energy efficiency, as well as to extend the scope of this technology to other heterogeneous catalytic reactions.

\section{METHODS}

All the experiments were performed under argon atmosphere either in a glovebox or using a vacuum line. Mesitylene, toluene and tetrahydrofurane (THF) were obtained from VWR Prolabo, then purified on alumina desiccant and degassed by bubbling Ar through the solution for 20 minutes. The commercial products, hexadecylamine (HDA, 99\%) and palmitic acid (PA, 99\%) were obtained from Sigma-Aldrich. The $\mathrm{Pt}_{2}(\mathrm{dba})_{3}$ precursor, bis(amido)iron(II) dimer $\left[\mathrm{Fe}\left\{\mathrm{N}\left(\mathrm{SiMe}_{3}\right)_{2}\right\}_{2}\right]_{2}$ and $\left[\mathrm{Co}\left\{\mathrm{N}\left(\mathrm{SiMe}_{3}\right)_{2}\right\}_{2}(\mathrm{THF})\right]$ were obtained from Nanomeps. The $\mathrm{Ni}(\mathrm{COD})_{2}$, $(\mathrm{COD}=$ cyclo-octadiene $)$ precursor and the $\mathrm{Bu}_{3} \mathrm{SnH}(1 \mathrm{M}$ in cyclohexane $)$ were obtained from Sigma Aldrich. All commercial compounds were stocked in the glove-box and used without further treatment. Siralox-5๑ was provided by Sasol, kept in the glove-box and used without further treatment. All gasses were supplied by Air-Liquide with the following purity: $\mathrm{CO}_{2}$ Alphagaz N48, $\mathrm{H}_{2} \mathrm{~N} 55$, Ar N56, $\mathrm{CH}_{4} \mathrm{~N} 55$.

$\mathrm{HDAHCl}$ was prepared according to a previously reported protocol. ${ }^{42}$ Briefly, $3 \mathrm{~g}$ of HDA were dissolved in $300 \mathrm{~mL}$ of pentane. 1,4 equivalents of $\mathrm{HCl}$ in diethylether $(1 \mathrm{M}, 17.5 \mathrm{~mL})$ were added and the mixture was let to stir during $30 \mathrm{~min}$. The mixture was let to decant and the supernatant was removed. Three washing steps with $200 \mathrm{~mL}$ pentane were performed before collecting the white $\mathrm{HDAHCl}$ powder and drying it under vacuum.

\section{Preparation of the heating agents}


$\mathbf{F e}_{0.5} \mathbf{C o}_{0.5}-\mathrm{NPs}$ were obtained by $\left[\mathrm{Fe}\left\{\mathrm{N}\left(\mathrm{SiMe}_{3}\right)_{2}\right\}_{2}\right]_{2}$ and $\quad\left[\mathrm{Co}\left\{\mathrm{N}\left(\mathrm{SiMe}_{3}\right)_{2}\right\}_{2}(\mathrm{THF})\right]$ decomposition under reductive atmosphere. ${ }^{14}$ First, $2.4 \mathrm{mmol}(667 \mathrm{mg})$ of HDAHCl were dispersed in $16 \mathrm{~mL}$ mesitylene. $0.4 \mathrm{mmol}$ of $\left[\mathrm{Fe}\left\{\mathrm{N}\left(\mathrm{SiMe}_{3}\right)_{2}\right\}_{2}\right]_{2}(301 \mathrm{mg})$ (i.e. $0.8 \mathrm{mmol}$ of $\mathrm{Fe}$ ) and $0.8 \mathrm{mmol}\left[\mathrm{Co}\left\{\mathrm{N}\left(\mathrm{SiMe}_{3}\right)_{2}\right\}_{2}(\mathrm{THF})\right](361.4 \mathrm{mg})$ were both dissolved in $5 \mathrm{~mL}$ mesitylene before being mixed together and being added to the HDAHCl dispersion forming a deep blue solution. $3.2 \mathrm{mmol} \mathrm{HDA}(772.7 \mathrm{mg})$ were dissolved in $10 \mathrm{~mL}$ and added to the solution. Finally, $4 \mathrm{~mL}$ of mesitylene were used to recover any remaining reactants from the vials. The dark blue solution was transferred to a Fischer-Porter reactor and vigorously stirred (700 rpm) for one hour at $150^{\circ} \mathrm{C}$ under $\mathrm{Ar}$ atmosphere. Then, 3 bars of $\mathrm{H}_{2}$ were introduced in the reactor and the mixture was let for $24 \mathrm{~h}$ under stirring $(700 \mathrm{rpm})$ at $150^{\circ} \mathrm{C}$. Finally, the reaction was stopped and decantation of NPs was assisted by a magnet before removing the supernatant. After three washing steps $(3 \times 5 \mathrm{~mL})$ with THF and drying, about $70 \mathrm{mg}$ NPs of $85 \%$ metal content (determined by ICP) were obtained.

All $\mathbf{F e}_{\mathrm{y}} \mathrm{Co}_{\mathrm{x}}-\mathbf{N P s}(\mathrm{y}=1-\mathrm{x})$ were obtained by adjusting the relative amounts of $\mathrm{Fe}$ and Co precursors and following the same procedure as for the $\mathrm{Fe}_{0.5} \mathrm{Co}_{0.5}$ - $\mathrm{NPs}$ (see Scheme 1). The total metal amount and concentration were kept constant with respect to the ligand, that is, 1.5 and 2 equivalents of $\mathrm{HDAHCl}(667 \mathrm{mg})$ and $\mathrm{HDA}(772.7 \mathrm{mg})$ respectively with respect to the total metal equivalents.

Fe-NPs were prepared by following an already published procedure: ${ }^{23}$ in the glove box, 2.62 mmol of PA (666.4 mg) dissolved in $20 \mathrm{~mL}$ of degassed mesitylene were added to a green solution of $1.00 \mathrm{mmol}$ of $\left[\mathrm{Fe}\left\{\mathrm{N}\left(\mathrm{SiMe}_{3}\right)_{2}\right\}_{2}\right]_{2}(753.2 \mathrm{mg})$ in $10 \mathrm{~mL}$ of mesitylene in a Fischer Porter bottle. The solution turned from green to yellow. Then, $2.00 \mathrm{mmol}$ of HDA (483.0 mg) dissolved in $10 \mathrm{~mL}$ of mesitylene were added. The bottle was pressurized with $\mathrm{H}_{2}$ (2 bar) and 
placed in an oil bath at $150^{\circ} \mathrm{C}$ for $72 \mathrm{~h}$ under vigorous magnetic stirring (400 rpm). The reaction was stopped, and the NPs were recovered by decantation assisted by a magnet. The mixture was introduced into the glove box and washed 3 times $(3 \times 10 \mathrm{~mL})$ with toluene and 3 times $(3 \times 10$ $\mathrm{mL}$ ) with THF. Then, the NPs were dried under vacuum. The $110 \mathrm{mg}$ black powder obtained contained $\sim 75 \mathrm{wt} \%$ of iron as evaluated by TGA analysis. FeC-NPs were obtained by dispersing the Fe-NPs $(70 \mathrm{mg})$ in $10 \mathrm{~mL}$ mesitylene in an atmosphere of $1: 1 \mathrm{CO}: \mathrm{H}_{2}$ for 5 days at $150^{\circ} \mathrm{C}$ under stirring $(400 \mathrm{rpm})^{7}$. After washing with toluene $(3 \times 5 \mathrm{~mL})$ and drying, the FeC-NPs $(50$ $\mathrm{mg}$ ) were obtained as a dark powder.

\section{Catalyst preparation}

The Ni/Siralox-5@ catalyst (10\% Ni loading) was prepared by the decomposition of $\mathrm{Ni}(\mathrm{COD})_{2}$ in the presence of Siralox-5( $\odot$ in mesitylene. In a typical preparation $1560 \mathrm{mg} \mathrm{Ni}(\mathrm{COD})_{2}(5.8$ mmol Ni) were dissolved in $20 \mathrm{~mL}$ mesitylene and $3 \mathrm{~g}$ Siralox-5C were added to the solution. The mixture was heated at $150^{\circ} \mathrm{C}$ under $\mathrm{Ar}$ atmosphere and vigorous stirring during $1 \mathrm{~h}$, followed by 3 washing steps with toluene. Drying under vacuum yielded $3.5 \mathrm{~g}$ of a black powder of Ni NPs (2-4 nm) impregnated on Siralox-5.

For PtSn-Siralox-5 $\odot$ catalysts ( $0.5 \%$ loading), the catalyst was prepared by mixing the support with preformed PtSn NPs with the Siralox-5@. In a typical preparation of Pt-NPs, $6.5 \mathrm{mg}$ of $\mathrm{Pt}_{2}(\mathrm{dba})_{3}(0.01 \mathrm{mmol} \mathrm{Pt})$ in $5 \mathrm{~mL}$ of THF were stirred in the presence of 1 bar CO for 20 minutes. The dark brown mixture formed was evaporated to a small volume (1-2 $\mathrm{mL})$. Complete drying has to be avoided in order to facilitate nanoparticle re-dispersion. Three washing steps by pentane were then performed before diluting with THF the obtained NPs to a $10 \mathrm{~mL}$ volume. 7.7 $\mu \mathrm{L} \mathrm{Bu} 3 \mathrm{SnH}(0.03 \mathrm{mmol} \mathrm{Sn})$ were added to the suspension of the Pt NPs and the solution was let 
under magnetic stirring for 5 to 10 minutes. $450 \mathrm{mg}$ of Siralox-5( $)$ were added and the mixture was let under magnetic stirring for 5 to 10 minutes. The solvent was eliminated under sonication to obtain a fine pale brown powder that was collected and stored in the glove-box.

In a final step, the supported catalysts were dispersed in $10 \mathrm{~mL}$ THF in a Fischer Porter reactor. The required quantity of NHAs in order to obtain a $10 \mathrm{wt} \%$ loading in the final catalyst were added to the dispersion and the mixture was sonicated for at least $30 \mathrm{~min}$ before being dried under vacuum and simultaneous sonication. The fine dark powder was collected, characterized and stored.

\section{Characterization}

The size and the morphology of the NPs were studied by transmission electron microscopy (TEM). TEM grids were prepared by deposition of one drop of a colloidal solution containing the NPs on a copper grid covered with amorphous carbon. Conventional bright-field images were performed using JEOL microscopes (Model 1011) working at $100 \mathrm{kV}$. HRTEM STEM and EELS analyses were performed on a Probe Corrected JEOL JEM-ARM200F Cold FEG equipped with a High Angle EDX detector working at $200 \mathrm{kV}$ and EDX analyses were performed using a TEM JEOL JEM 2100F.

XRD measurements were performed on a PANalytical Empyrean diffractometer using Co-K $\alpha$ radiation $(\lambda=0.1789 \mathrm{~nm})$ at $45 \mathrm{kV}$ and $40 \mathrm{~mA}$. The crystallite size L has been assessed by Scherrer expression:

$L=0,94 \frac{\lambda}{F W H M \cdot \cos (\theta)}$

with $\lambda=0,1789 \mathrm{~nm}$ and FWHM the Full Width at Half Maximum 
Microanalysis (ICP-MS) has been performed by Mikroanalytisches Labor Pascher (Remagen, Germany) under inert atmosphere. Thermogravimetric analyses (TGA) were performed in a TGA/DSC 1 STAR System equipped with an ultra-microbalance UMX5, a gas switch GC200 and sensors DTA and DSC.

The iron state and its environment were characterized by Mössbauer spectroscopy (WISSEL,

${ }^{57} \mathrm{Co}$ source). Mössbauer spectra were measured at $4 \mathrm{~K}$. The quantitative analysis was performed using Recoil software fitting the data by Lorentzian shape peaks and applying a least-squares method.

Magnetic measurements were performed on a Vibrating Sample Magnetometer (VSM, Quantum Device PPMS Evercool II). XRD and VSM studies were carried out on compact powder samples that were prepared and sealed under argon atmosphere.

\section{Specific absorption rate measurements}

The specific absorption rate (SAR) of the NPs has been measured by calorimetry. Two types of measurements have been performed: (i) the low-temperature SAR routinely estimated on samples of NP dispersions in a solvent, and (ii) the temperature dependence of the SAR, measured up to high-temperature, performed on solid-state samples, where the NPs are dispersed on a catalyst support. These two types of measurements are detailed hereafter.

\section{Low-temperature SAR of NPs in liquid.}

An air-tight tube containing about $10 \mathrm{mg}$ of heating agents dispersed in $0.5 \mathrm{~mL}$ of mesitylene was filled under inert atmosphere. The tube was then placed in a calorimeter containing $2.5 \mathrm{~mL}$ of deionized water, the temperature of which was monitored during the experiment. The 
calorimeter was exposed to an alternating magnetic field for a time varying between 5 and $20 \mathrm{~s}$ so that the temperature rise never exceeded $20^{\circ} \mathrm{C}$. The temperature rise at the end of the magnetic field application was always measured after shaking the calorimeter to ensure the temperature homogeneity, which was measured by two probes (at the top and the bottom of the calorimeter). The temperature rise was determined after this process, from the mean slope of the $\Delta \mathrm{T} / \Delta \mathrm{t}$ function. The raw SAR values were calculated using the expression:

$$
S A R=\frac{\sum_{\mathrm{i}} \mathrm{C}_{\mathrm{pi}} \mathrm{m}_{\mathrm{i}}}{\mathrm{m}_{\mathrm{met}}} \times \frac{\Delta \mathrm{T}}{\Delta \mathrm{t}}
$$

where $C \mathrm{p}_{\mathrm{i}}$ and $\mathrm{m}_{\mathrm{i}}$ are the specific heat capacity and the mass for each component respectively $\left(C \mathrm{p}=449 \mathrm{~J} \cdot \mathrm{kg}^{-1} \cdot \mathrm{K}^{-1}\right.$ for Fe NPs, $C \mathrm{p}=1750 \mathrm{~J} \cdot \mathrm{kg}^{-1} \cdot \mathrm{K}^{-1}$ for mesitylene, $C \mathrm{p}=4186 \mathrm{~J} \cdot \mathrm{kg}^{-1} \cdot \mathrm{K}^{-1}$ for water and $C \mathrm{p}=720 \mathrm{~J} \cdot \mathrm{kg}^{-1} \cdot \mathrm{K}^{-1}$ for glass), and $m_{m e t}$ is the mass of the metallic compound in the sample.

The raw SAR values were corrected from the calorimeter losses, which were previously calibrated. For the calibration, a sample containing nanoparticles displaying moderate SAR was exposed for different time periods to an alternating magnetic field of $47 \mathrm{mT}, 100 \mathrm{kHz}$. The SAR of the sample was measured for each exposure period. The SAR measured for an exposure time of $5 \mathrm{~s}$ is considered as the "real" SAR (no losses). For longer exposure times, the difference between the measured SAR and the "real" SAR allows the determination of a corrective factor. The calibration data are displayed in Figure S10 and Table S5.

Temperature dependence of the SAR for NPs in a solid-state sample

This protocol concerns the samples where NPs are immobilized on Siralox-5๑. The temperature was measured with a pyrometer IN5-Plus from LumaSense Technology (8-14 $\mu \mathrm{m}$, $32-900^{\circ} \mathrm{C}$ ). The sample was placed in a dedicated calorimeter made of quartz, with a $\mathrm{ZnSe}$ window on the top, to allow the infrared emission reaching the pyrometer while keeping the 
sample under inert atmosphere. The temperature increase was measured while applying the magnetic alternating field (heating curve), and the temperature decrease after turning off the field (cooling curve). We have computed the SAR at each temperature by subtracting the slope of the heating curve from the slope of the cooling curve at the same temperature, following Varsano et al. ${ }^{11}$ The temperature dependence of $\mathrm{C}_{\mathrm{p}}$ values of $\mathrm{Fe}$ and $\mathrm{Co}$ have been obtained from Touloukian et al. ${ }^{43}$ The $C_{p}$ values of $\mathbf{F e}_{\mathbf{x}} \mathbf{C o}_{1-\mathbf{x}}-\mathbf{N P}$ have been calculated by considering the atomic fraction weighted average of the $\mathrm{C}_{\mathrm{p}}$ of iron and the $\mathrm{C}_{\mathrm{p}}$ of Co.

\section{Catalytic tests}

Catalytic tests were performed in a quartz tube continuous-flow reactor of $1 \mathrm{~cm}$ diameter surrounded by an inductor delivering an $\mathrm{AC}$ magnetic field oscillating at a frequency of $300 \mathrm{kHz}$ with a rms amplitude adjustable between 0 and $65 \mathrm{mT}$. The induction coil is $3 \mathrm{~cm}$ wide and $2 \mathrm{~cm}$ high. The quartz reactor with the catalyst was located at the centre of the coil, where the magnetic field is homogeneous. We systematically used $400 \mathrm{mg}$ of catalytic bed (heating agent, catalytic NPs and support) to perform the catalytic tests. Before starting the experiment, the line was purged three times with the corresponding to each reaction reactants. Mass flows of $\mathrm{C}_{3} \mathrm{H}_{8}$ : $\mathrm{CO}_{2}$ 1:3 $\left(10 \mathrm{~mL} / \mathrm{min}: 30 \mathrm{~mL} / \mathrm{min}\right.$, Weight hourly space velocity, (WHSV), $\left.60 \mathrm{~L} \cdot \mathrm{h}^{-1} \cdot \mathrm{g}_{(\mathrm{Ni})}{ }^{-1}\right)$ and $\mathrm{CH}_{4}: \mathrm{CO}_{2}$ 1:1 $\left(10 \mathrm{~mL} / \mathrm{min}: 10 \mathrm{~mL} / \mathrm{min}\right.$, WHSV $\left.30 \mathrm{~L} \cdot \mathrm{h}^{-1} \cdot \mathrm{g}_{(\mathrm{Ni})}{ }^{-1}\right)$ were supplied at the inlet for PDR and for MDR respectively. $20 \mathrm{~mL} / \mathrm{min}$ pure propane was supplied for PDH (WHSV $600 \mathrm{~L} \cdot \mathrm{h}^{-}$

$\left.{ }^{1} \cdot \mathrm{g}_{(\mathrm{Pt})}{ }^{-1}\right)$. The Sabatier reaction at $300 \mathrm{kHz}$ was performed in continuous flow at $5 \mathrm{~mL} / \mathrm{min} \mathrm{CO}_{2}$ and $20 \mathrm{~mL} / \mathrm{min}_{2}$ and in batch reactor at $100 \mathrm{kHz}$ and $50 \mathrm{kHz}$ with 3 bar $\mathrm{CO}_{2}, 1$ bar $\mathrm{H}_{2}$. During catalysis, the temperature was monitored using an infrared camera $\left(0-1300^{\circ} \mathrm{C}\right.$ range, Testo 885$)$. The temperature measured by this set-up corresponds to the reactor wall temperature, it is thus, 
underestimated with respect to the real catalyst temperature. The outgoing gases were injected in a Gas Chromatography-Mass Spectrometry (PerkinElmer 580 Gas Chromatograph-Thermal Conductivity Detector coupled to a Clarus SQ8T Mass Spectrometer). GC calibration has been performed with pure gases. The response factor of the analytes $\mathrm{RF}_{\mathrm{i}}$ was determined by injecting well-known quantities of each analyte $\mathrm{i}$ into the column. The area of the peak of the species $\mathrm{i}$ on the chromatogram $\left(\mathrm{A}_{\mathrm{i}}\right)$ enables to determine the conversion of $\mathrm{i}\left(\mathrm{X}_{\mathrm{i}}\right)$ and the selectivity toward $\mathrm{j}$ $\left(\mathrm{S}_{\mathrm{j}}\right)$ based on the relations shown in Scheme 2. An example of the products analyzed for the dehydrogenation of propane is given in Scheme 3. For the dry reforming of alkanes, the conversion is calculated on the alkane basis, as $\mathrm{CO}_{2}$ is expected to be supplied in excess.

Scheme 2. Calculation of propane conversion $\left(\mathrm{X}_{\text {propane }}\right)$ and propene selectivity $\left(\mathrm{S}_{\text {propene }}\right)$

$$
\begin{gathered}
X_{\text {propane }}=\frac{\sum_{\text {products }} R F_{\text {Product }, i} \cdot A_{\text {Product }, i}}{\sum_{\text {products }} R F_{\text {Product }, i} \cdot A_{\text {Product }, i}+\sum_{\text {reactant }} R F_{\text {reactant }, i} \cdot A_{\text {reactant }, i}} \\
S_{\text {propene }}=\frac{R F_{\text {Propene }} \cdot A_{\text {Propene }}}{\sum_{\text {products }} R F_{\text {Product }, i} \cdot A_{\text {Product }, i}}
\end{gathered}
$$

Scheme 3. Propane dehydrogenation into propene and side products

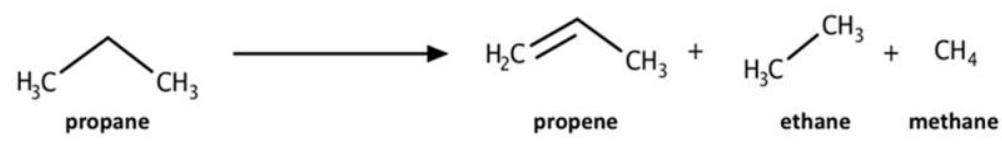




\section{Supporting Information.}

The following file is available free of charge

Section S1. Composition and structure of NHAs; Section S2: Mössbauer Spectroscopy; Section S3: SAR (T) measurements for $\mathrm{Fe}_{\mathrm{x}} \mathrm{Co}_{\mathrm{y}}-\mathrm{NPs}$ supported on Siralox-5C; Section S4: Macroscopic chain formation of the $\mathrm{Fe}_{0.7} \mathrm{Co}_{0.3}$-NPs and $\mathrm{Fe}_{0.8} \mathrm{Co}_{0.2}$-NPs supported on Siralox-5(C; Section S5: $\mathrm{Fe}_{0.5} \mathrm{Co}_{0.5}$-NPs Catalysis of before and after Sabatier reaction; Section S6: Gas Chromatogram, PDR; Section S7: Pt and PtSn nanoparticles; Section S8: Gas Chromatograms, PDH; Section S9: Detailed catalytic results of PDH; Section S10. SAR: Calorimeter calibration. (file type, PDF)

\section{AUTHOR INFORMATION}

\section{Corresponding Authors}

* E-mail: chaudret@insa-toulouse.fr

* E-mail: julian.carrey@insa-toulouse.fr

* E-mail:ksoulant@insa-toulouse.fr

\section{Author Contributions}

The manuscript was written through contributions of all authors. All authors have given approval to the final version of the manuscript. $\$$ These authors contributed equally. (match statement to author names with a symbol)

\section{Funding Sources}


Th authors gratefully acknowledge funding from the ERC Advanced Grant MONACAT 2015694159.

\section{ACKNOWLEDGMENT}

This project has received funding from the European Research Council (ERC) under the European Union's Horizon 2020 research and innovation program (grant agreement No [694159] MONACAT). 


\section{REFERENCES}

(1) Hergt, R.; Dutz, S.; Müller, R.; Zeisberger, M. Magnetic particle hyperthermia: nanoparticle magnetism and materials development for cancer therapy. J. Phys. Condens. Matter 2006, 18, S2919-S2934.

(2) Hervault, A.; Thanh, N. T. K. Magnetic nanoparticle-based therapeutic agents for thermochemotherapy treatment of cancer. Nanoscale 2014, 6, 11553-11573.

(3) Salunkhe, A. B.; Khot, V. M.; Pawar, S. H. Magnetic Hyperthermia with Magnetic Nanoparticles: A Status Review. Curr. Top. Med. Chem. 2014, 14, 572-594.

(4) Hartwig, J.; Ceylan, S.; Kupracz, L.; Coutable, L.; Kirschning, A. Heating under High-Frequency Inductive Conditions: Application to the Continuous Synthesis of the Neurolepticum Olanzapine (Zyprexa). Angew. Chem. - Int. Ed. 2013, 52, 9813-9817.

(5) Ceylan, S.; Coutable, L.; Wegner, J.; Kirschning, A. Inductive Heating with Magnetic Materials inside Flow Reactors. Chem. - A Eur. J. 2011, 17, 1884-1893.

(6) Meffre, A.; Mehdaoui, B.; Connord, V.; Carrey, J.; Fazzini, P. F.; Lachaize, S.; Respaud, M.; Chaudret, B. Complex Nano-objects Displaying Both Magnetic and Catalytic Properties: A Proof of Concept for Magnetically Induced Heterogeneous Catalysis. Nano Lett. 2015, 15, 32413248.

(7) Bordet, A.; Lacroix, L. M.; Fazzini, P. F.; Carrey, J.; Soulantica, K.; Chaudret, B. Magnetically Induced Continuous $\mathrm{CO}_{2}$ Hydrogenation Using Composite Iron Carbide Nanoparticles of Exceptionally High Heating Power. Angew. Chemie - Int. Ed. 2016, 55, 15894 15898. 
(8) Mortensen, P. M.; Engbæk, J. S.; Vendelbo, S. B.; Hansen, M. F.; Østberg, M. Direct Hysteresis Heating of Catalytically Active Ni-Co Nanoparticles as Steam Reforming Catalyst. Ind. Eng. Chem. Res. 2017, 56, 14006-14013.

(9) Vinum, M. G.; Almind, M. R.; Engbaek, J. S.; Vendelbo, S. B.; Hansen, M. F.; Frandsen, C.; Bendix, J.; Mortensen, P. M. Dual-Function Cobalt-Nickel Nanoparticles Tailored for High-Temperature Induction-Heated Steam Methane Reforming. Angew. Chemie Int. Ed. 2018, $57,10569-10573$.

(10) Niether, C.; Faure, S.; Bordet, A.; Deseure, J.; Chatenet, M.; Carrey, J.; Chaudret, B.; Rouet, A. Improved water electrolysis using magnetic heating of FeC-Ni core-shell nanoparticles. Nat. Energy 2018, 3, 476-483.

(11) Varsano, F.; Bellusci, M.; La Barbera, A.; Petrecca, M.; Albino, M.; Sangregorio, C. Dry reforming of methane powered by magnetic induction. Int. J. Hydrogen Energy 2019, 44, 21037 21044.

(12) Wang, W.; Duong-Viet, C.; Xu, Z.; Ba, H.; Tuci, G.; Giambastiani, G.; Liu, Y.; TruongHuu, T.; Nhut, J.-M.; Pham-Huu, C. $\mathrm{CO}_{2}$ methanation under dynamic operational mode using nickel nanoparticles decorated carbon felt (Ni/OCF) combined with inductive heating. Catal. Today, 2019, DOI:10.1016/j.cattod.2019.02.050.

(13) Pérez-Camacho, M. N.; Abu-Dahrieh, J.; Rooney, D.; Sun, K. Biogas reforming using renewable wind energy and induction heating. Catal. Today 2015, 242, 129-138.

(14) Garnero, C.; Lepesant, M.; Garcia-Marcelot, C.; Shin, Y.; Meny, C.; Farger, P.; WarotFonrose, B.; Arenal, R.; Viau, G.; Soulantica, K. ; Fau, P.; Poveda, P.; Lacroix, L.-M.; Chaudret, 
B. Chemical Ordering in Bimetallic FeCo Nanoparticles: From a Direct Chemical Synthesis to Application As Efficient High-Frequency Magnetic Material. Nano Lett. 2019, 19, 1379-1386.

(15) Kale, S. S.; Asensio, J. M.; Estrader, M.; Werner, M.; Bordet, A.; Yi, D.; Marbaix, J.; Fazzini, P.-F.; Soulantica, K.; Chaudret, B. Iron carbide or iron carbide/cobalt nanoparticles for magnetically-induced $\mathrm{CO}_{2}$ hydrogenation over Ni/SiRAlOx catalysts. Catal. Sci. Technol. 2019, 9, 2601-2607.

(16) Pfeiffer, F.; Radeloff, C. Soft magnetic Ni-Fe and Co-Fe alloys-some physical and metallurgical aspects. J. Magn. Magn. Mater. 1980, 19, 190-207.

(17) a) Ghemes A.; Dragos-Pinzaru O.; Chiriac, H.; Lupu, N.; Grigoras, M.; Shore, D.; Stadler B.; Tabakovic, I. Controlled Electrodeposition and Magnetic Properties of Co35Fe65 Nanowires with High Saturation Magnetization. J. Electrochem. Soc., 2017, 164, D13-D22; b) Alonso, J.; Khurshid, H.; Sankar, V.; Nemati, Z.; Phan, M. H.; Garayo, E.; Garcia J. A.; Srikanth, H. FeCo nanowires with enhanced heating powers and controllable dimensions for magnetic hyperthermia J. Appl. Phys., 2015, 117, 17D113.

(18) Shore, D.; Ghemes, A.; Dragos-Pinzaru, O.; Gao, Z.; Shao, Q.; Sharma, A.; Um, J.; Tabakovic, I.; Bischof, J. C.; Stadler, B. J. H. Nanowarming using Au-tipped Co35Fe65ferromagnetic nanowires. Nanoscale, 2019, 11, 14607-14615

(19) Le Caer, G.; Dubois, J. M.; Pijolat, M.; Perrichon, V.; Bussiere, P. Characterization by Moessbauer spectroscopy of iron carbides formed by Fischer-Tropsch synthesis. J. Phys. Chem. 1982, 86, 4799-4808. 
(20) Carrey, J.; Mehdaoui, B.; Respaud, M. Simple models for dynamic hysteresis loop calculations of magnetic single-domain nanoparticles: Application to magnetic hyperthermia optimization. J. Appl. Phys. 2011, 109, 083921.

(21) Meffre, A.; Mehdaoui, B.; Kelsen, V.; Fazzini, P. F.; Carrey, J.; Lachaize, S.; Respaud, M.; Chaudret, B. A simple chemical route toward monodisperse iron carbide nanoparticles displaying tunable magnetic and unprecedented hyperthermia properties. Nano Lett. 2012, 12, $4722-4728$.

(22) Dumestre, F.; Chaudret B.; Amiens, C.; Renaud, P.; Fejes, P. Superlattices of Iron Nanocubes Synthesized from Fe[N((SiMe $\left.)_{2}\right]_{2}$. Science 2004, 303, 821-823.

(23) Lacroix, L.; Lachaize, S.; Falqui, A.; Chaudret, B. Iron nanoparticle growth in organic superstructures. J. Am. Chem. Soc. 2009, 131, 549-557.

(24) Bordet, A.; Asensio, J. M.; Soulantica, K.; Chaudret, B. Enhancement of Carbon Oxides Hydrogenation on Iron-Based Nanoparticles by In-Situ Water Removal. ChemCatChem 2018, $10,4047-4051$.

(25) Asensio, J. M.; Marbaix, J.; Mille, N.; Lacroix, L.-M.; Soulantica, K.; Fazzini, P.-F.; Carrey, J.; Chaudret, B. To heat or not to heat: a study of the performances of iron carbide nanoparticles in magnetic heating. Nanoscale 2019, 11, 5402-5411.

(26) Petrov, Y. I.; Shafranovskii, E. A. Discrete distribution of hyperfine fields at the Fe nuclei in Fe-Co nanoparticles. Dokl. Phys. Chem. 2006, 411 (2), 339-344.

(27) Petrov, Y. I.; Shafranovsky, E. A. Structure and Magnetic Properties of Aerosol Nanoparticles of Fe and Its Alloys. Int. J. Inorg. Chem. 2012, 2012, 1-43. 
(28) Cullity, B. D.; Graham, C. D. Introduction to Magnetic Materials; John Wiley \& Sons, Inc.: Hoboken, NJ, USA, 2008; Vol. 21.

(29) Jiles D. in Introduction to Magnetism and Magnetic Materials, 1st ed (Chapman and Hall, London; New York, 1991).

(30) Lacroix, L. M.; Malaki, R. B.; Carrey, J.; Lachaize, S.; Respaud, M.; Goya, G. F.; Chaudret, B. Magnetic hyperthermia in single-domain monodisperse FeCo nanoparticles: Evidences for Stoner-Wohlfarth behavior and large losses. J. Appl. Phys. 2009, 105, 023911.(31) Mehdaoui, B.; Tan, R. P.; Meffre, A.; Carrey, J.; Lachaize, S.; Chaudret, B.; Respaud, M. Increase of magnetic hyperthermia efficiency due to dipolar interactions in lowanisotropy magnetic nanoparticles: Theoretical and experimental results. Phys. Rev. B 2013, 87, 174419.

(32) Garbarino, G.; Bellotti, D.; Riani, P.; Magistri, L.; Busca, G. Methanation of carbon dioxide on $\mathrm{Ru} / \mathrm{Al}_{2} \mathrm{O}_{3}$ and $\mathrm{Ni} / \mathrm{Al}_{2} \mathrm{O}_{3}$ catalysts at atmospheric pressure: Catalysts activation, behaviour and stability. Int. J. Hydrogen Energy 2015, 40 (30), 9171-9182.

(33) Schwengber, C. A.; Da Silva, F. A.; Schaffner, R. A.; Fernandes-Machado, N. R. C.; Ferracin, R. J.; Bach, V. R.; Alves, H. J. Methane dry reforming using $\mathrm{Ni} / \mathrm{Al}_{2} \mathrm{O}_{3}$ catalysts: Evaluation of the effects of temperature, space velocity and reaction time. J. Environ. Chem. Eng. 2016, 4, 3688-3695.

(34) Siahvashi, A.; Chesterfield, D.; Adesina, A. A. Propane $\mathrm{CO}_{2}$ (dry) reforming over bimetallic Mo-Ni/ $\mathrm{Al}_{2} \mathrm{O}_{3}$ catalyst. Chem. Eng. Sci. 2013, 93, 313-325. 
(35) Olafsen, A.; Daniel, C.; Schuurman, Y.; Råberg, L. B.; Olsbye, U.; Mirodatos, C. Light alkanes $\mathrm{CO}_{2}$ reforming to synthesis gas over Ni based catalysts. Catal. Today 2006, 115, 179185.

(36) Råberg, L. B.; Jensen, M. B.; Olsbye, U.; Daniel, C.; Haag, S.; Mirodatos, C.; Sjåstad, A. O. Propane dry reforming to synthesis gas over Ni-based catalysts: influence of support and operating parameters on catalyst activity and stability. J. Catal. 2007, 249, 250-260.

(37) Sattler, J. J. H. B.; Ruiz-Martinez, J.; Santillan-Jimenez, E.; Weckhuysen, B. M. Catalytic dehydrogenation of light alkanes on metals and metal oxides. Chem. Rev. 2014, 114, 1061310653.

(38) Lee, M. H.; Nagaraja, B. M.; Lee, K. Y.; Jung, K. D. Dehydrogenation of alkane to light olefin over PtSn $/ \theta-\mathrm{Al}_{2} \mathrm{O}_{3}$ catalyst: Effects of Sn loading. Catal. Today 2014, 232, 53-62.

(39) Zhu, H.; Anjum, D. H.; Wang, Q.; Abou-Hamad, E.; Emsley, L.; Dong, H.; Laveille, P.; Li, L.; Samal, A. K.; Basset, J. M. Sn surface-enriched Pt-Sn bimetallic nanoparticles as a selective and stable catalyst for propane dehydrogenation. J. Catal. 2014, 320, 52-62.

(40) Nagaraja, B. M.; Shin, C. H.; Jung, K. D. Selective and stable bimetallic PtSn/ $\theta-A 12 O 3$ catalyst for dehydrogenation of n-butane to n-butenes. Appl. Catal. A Gen. 2013, 467, 211-223.

(41) Jahangiri, H.; Bennett, J.; Mahjoubi, P.; Wilson, K.; Gu, S. A review of advanced catalyst development for Fischer-Tropsch synthesis of hydrocarbons from biomass derived syn-gas. Catal. Sci. Technol. 2014, 4, 2210-2229. 
(42) Soulantica, K.; Maisonnat, A.; Fromen, C.; Casanove M-J.; Chaudret, B. Spontaneous formation of ordered 3D superlattices of nanocrystals from polydisperse colloidal solutions. Angew. Chemie - Int. Ed., 2003, 1945-1949.

(43) Touloukian Y. S.; Buyco E. H., 'Thermophysical Properties of Matter - The TPRC Data Series. Volume 4. Specific Heat - Metallic Elements and Alloys', Thermophysical and electronic properties information analysis center Lafayette in, Jan. 1971. 


\section{Abstract graphic}

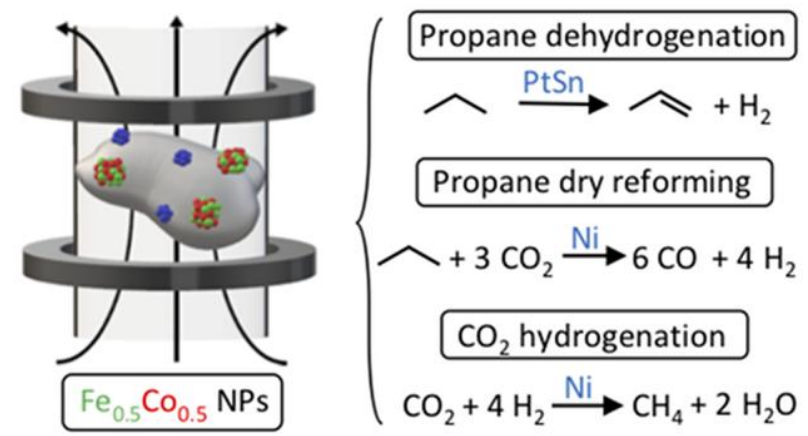

